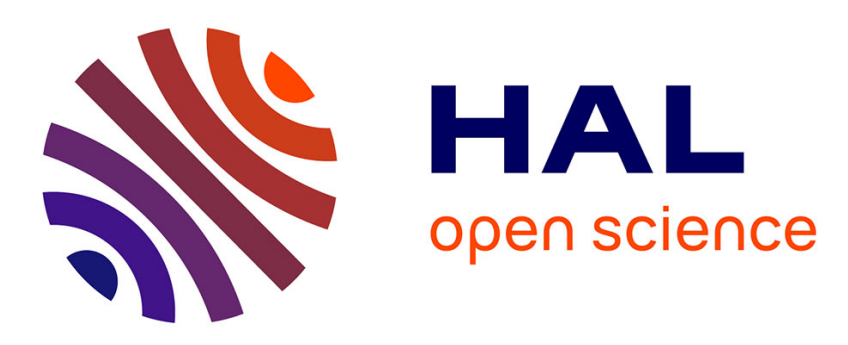

\title{
Effect of high-content Yttria on the thermal expansion behaviour and ionic conductivity of a stabilised cubic Hafnia
}

\author{
Louise Sévin, Volatiana Razafindramanana, Aurélie Julian-Jankowiak, \\ Jean-François Justin, Fabrice Mauvy, Francis Rebillat
}

\section{To cite this version:}

Louise Sévin, Volatiana Razafindramanana, Aurélie Julian-Jankowiak, Jean-François Justin, Fabrice Mauvy, et al.. Effect of high-content Yttria on the thermal expansion behaviour and ionic conductivity of a stabilised cubic Hafnia. Journal of the European Ceramic Society, 2020, 40 (15), pp.5859-5869. 10.1016/j.jeurceramsoc.2020.05.044 . hal-02872150

\section{HAL Id: hal-02872150 \\ https://hal.science/hal-02872150}

Submitted on 21 Jan 2022

HAL is a multi-disciplinary open access archive for the deposit and dissemination of scientific research documents, whether they are published or not. The documents may come from teaching and research institutions in France or abroad, or from public or private research centers.
L'archive ouverte pluridisciplinaire HAL, est destinée au dépôt et à la diffusion de documents scientifiques de niveau recherche, publiés ou non, émanant des établissements d'enseignement et de recherche français ou étrangers, des laboratoires publics ou privés. 


\title{
Effect of high-content Yttria on the thermal expansion behaviour and ionic conductivity of a stabilised cubic Hafnia
}

\author{
Louise Sévin $^{\text {abc }}$, Volatiana Razafindramanana ${ }^{\mathrm{ab}}$, AurélieJulian-Jankowiak ${ }^{\mathrm{a}}$, Jean-François Justin ${ }^{\mathrm{a}}$, Fabrice Mauvy ${ }^{\mathrm{c}}$, Francis \\ Rebillat $^{\mathrm{d}}$ \\ a DMAS, ONERA-Université Paris-Saclay, Chatillon F-92322, France \\ ${ }^{b}$ CNES - Centre National d'Etudes Spatiales, Toulouse, France \\ ${ }^{\mathrm{c}}$ CNRS, Université de Bordeaux, ICMCB, UMR 5026, 87 Avenue du Dr. Albert Schweitzer, Pessac Cedex, Bordeaux 33608 F, France \\ ${ }^{\mathrm{d}}$ Laboratoire des Composites Thermostructuraux, CNRS - CEA-SAFRAN, University of Bordeaux, 3 allée de la Boetie, Pessac Cedex, \\ Bordeaux 33600, France
}

\begin{abstract}
The needs for space propulsion thruster induce the development of new designs and material compositions able to withstand $3000 \mathrm{~K}$ of flame combustion temperature. Cubic-stabilised hafnia appears as one of the most promising candidates to protect refractory materials in such conditions. Here, the influence of dopant content on the thermal expansion (473-1823 K) and ionic conductivity $(600-1150 \mathrm{~K})$ in highly doped-hafnia $\left(12-33 \mathrm{~mol} \% \mathrm{Y}_{2} \mathrm{O}_{3}\right)$ with disordered cubic systems is reported. The composition and the homogeneity of the samples were carefully checked using crystallographic, chemical and spectroscopy analyses. Finally, the study of thermal and oxygen conductivity properties highlighted their dependence on the amount of dopant. The average thermal expansion coefficient was lowered from 11.3 to $10.910^{-6} / \mathrm{K}$ and the ionic conductivity decreased by two decades with $33 \mathrm{~mol} \%$ of $\mathrm{Y}_{2} \mathrm{O}_{3}$ by using the optimised substitution ratio. Interactions and local ordering of oxygen vacancies can explain this behaviour.
\end{abstract}

Keywords : Yttria doped hafnia ; Fluorite ; Thermal expansion coefficient (TEC) ; Ionic conductivity

*Corresponding author : at 29 avenue Division Leclerc, 92320 Chatillon, France.

E-mail address : $\underline{\text { louise.sevin@onera.fr }}$

\section{Introduction}

Lower emission and higher efficiency aeronautical and aerospace engines are constantly having their temperature capabilities pushed up and cooling fluxes limited to boost performance. Thus, new materials such as Thermal Barrier Coating and Environmental Barrier Coating (TBC/EBC) compositions and designs ${ }^{[1-4]}$ are developed. Particularly, studies on a greener space propulsion monopropellant have brought an upper range of flame combustion temperatures up to $3000 \mathrm{~K}$ with combustion products reaching $15 \mathrm{vol}$. \% of water vapour ${ }^{[5]}$. In this context of ultra-severe combustion environment, no known combination of materials is able to undergo such flame temperature in oxidative environment without the help of film cooling. Current solution of satellite thruster wall associates a ceramic oxide as TBC with one metallic layer underneath to protect the highly refractory materials component for $2000 \mathrm{~K}$ temperature flame application ${ }^{[6]}$. However, at higher temperature, the first metallic layer cannot be used due to its melting point ${ }^{[7]}$. It is thus challenging to develop an oxide ceramic playing the role of both thermal and diffusion barrier at these temperatures with a Thermal Expansion Coefficient (TEC) fitting with that of an ultra-high refractory material support with a quite low thermal expansion ( 5-7 106/K).

Among fluorite type oxides, hafnia (hafnium oxide, $\mathrm{HfO}_{2}$ ) is reported as one of the oxide ceramic with the highest melting point $(3073 \mathrm{~K})$, low thermal conductivity ${ }^{[8]}$, relatively low oxygen permeability and thermal expansion coefficient compared to others refractory oxides ${ }^{[9-12]}$. However, its thermal expansion (TEC $\left.=11-1210^{-6} / \mathrm{K}\right)$ is higher than ultra-high refractory materials $($ TEC $=5-$ $7.10^{-6} / \mathrm{K}$ ), leading to thermal stresses detrimental to the material stability. Moreover, pure hafnia like zirconia present during heating two reversible allotropic phase transitions : monoclinic to tetragonal at $1993 \mathrm{~K}$ and tetragonal to cubic at $2873 \mathrm{~K}[11,13,14]$. While cooling down, the tetragonal to monoclinic transition leads to a volume expansion around $3 \%{ }^{[11]}$. In the literature, TBC materials are generally yttria partially stabilised zirconia (YPSZ) with a dopant concentration around 4 mol\%, known for their favourable mechanical properties ${ }^{[15-17]}$. However, new materials such as zirconia pyrochlore phases ${ }^{[18-20]}$ are currently developed by substituting $50 \%$ of the host cations. A large number of studies have been devoted to these ordered phases, due to their higher thermal stability, CMAS-resistance and thermal expansion which can match those of nickel-based superalloys with the adapted rare earth cations ${ }^{[4,21,22]}$.

Nevertheless, these two compositions do not fulfil the requirements of high reliability needed in space propulsion. Indeed, phase decomposition at high temperature for both compositions is among others the main failure for ultra-high temperature applications ${ }^{[13,23,24]}$. 
The development of compatible thermal expansion EBC for new engines materials made of SiC also induced the development of mono or di-silicates rare earth coatings ${ }^{[1]}$ which couldn't be taken into account in this work because of their low melting point.

In recent studies, hafnia appears as a good candidate to be used as EBC ${ }^{[1]}$ as well as TBC ${ }^{[8,25]}$ for thruster improvement due to its excellent durability and stability at the studied temperature of $1923 \mathrm{~K}$. To get highly stable oxide ceramic up to $3000 \mathrm{~K}$ [11], the stabilisation of the cubic phase is fundamental since it eliminates the phase transition which brings cracks formation and their propagation during cycling. Trivalent rare earth oxide cations are commonly used to stabilise zirconia or hafnia. However, it implies the formation of oxygen vacancies in the oxygen sub-lattice to maintain electrical charge neutrality. Andrievskaya13 and other authors ${ }^{[26-29]}$ have demonstrated that the melting point, stability and thermal expansion coefficient of the solid solution strongly depend on the amount of content and the ionic radius of the dopant. However, only few studies have been undertaken so far to assess the influence of $\mathrm{Y}_{2} \mathrm{O}_{3}$ on the oxygen permeability of $\mathrm{HfO}_{2}$.

Indeed, until now, structural and ionic conductivity properties are generally investigated in fuel cell research field with the aim of increasing as much as possible the oxygen ion mobility of the material at the lowest temperature: this is the opposite of our need (i.e. drastically reduce oxygen ion mobility at high temperatures). For this, various authors have studied the influence of the nature and concentration of the dopant for stabilised ceria and zirconia having high oxygen ion conductivities ${ }^{[30,31]}$. For yttria stabilised zirconia with 8 mol\% of $\mathrm{Y}_{2} \mathrm{O}_{3}{ }^{[32]}$, a maximum in ionic conductivity is observed with a decrease for a lower or a higher doping rate.

This phenomenon is directly related to a reorganisation process of the oxygen vacancies. Moreover, other studies have shown the influence of the ionic radius. Indeed, fluorite systems composed of $\mathrm{HfO}_{2}$ doped with $\mathrm{Sc}^{3+}, \mathrm{Yb}^{3+}, \mathrm{Y}^{3+}, \mathrm{Tb}^{3+}, \mathrm{Gd}^{3+}$ or $\mathrm{Er}^{3+}$ as solid solution with different host cation $\left(\mathrm{Zr}^{4+}, \mathrm{Ce}^{4+}, \mathrm{Th}^{4+}, \mathrm{U}^{4+}\right)$ or pyrochlore systems ${ }^{[33-36]}$ exhibit an increase in the ionic conductivity with smaller ionic radius. Concerning the ionic conductivity measurements, several methods are used in the literature: Electrochemical Impedance Spectroscopy (EIS) ${ }^{[37]}$, direct oxygen permeability ${ }^{[38]}$ or isotope exchange depth profile ${ }^{[39]}$. According to these techniques, it has been demonstrated that the measured ionic conductivity could be directly related to the oxygen ion diffusion by the Nernst-Einstein equation ${ }^{[31,40,41]}$. The Haven ratio ${ }^{[42]}$ should be considered in the case of the evolution of oxygen vacancies concentration in the working temperature range.

Only few studies considered hafnia-based systems as potential material for fuel cell application since they exhibit a ionic conductivity $1.5-2.2$ times lower than optimised doped zirconia systems ${ }^{[43]}$. These values were anticipated by some theoretical prediction of ionic conductivity in solid state doped $\mathrm{HfO}_{2}{ }^{[44]}$. Moreover, the influence of the dopant on both thermal expansion and ionic conductivity has only been studied for a rather low content $(<15 \mathrm{~mol} \%)$ and with few investigations on the microstructure ${ }^{[45]}$. In fact, concerning fuel cells, only few studies are dedicated to hafnia-based systems and none of them aim to decrease both thermal expansion and ionic conductivity as needed for a pertinent high temperature EBC/TBC solution to protect a refractory material. However, the influence of the concentration of oxygen vacancies on hafnia based systems have been identified ${ }^{[41]}$. Thus, the main objective of the present study is to assess the influence of the oxygen vacancy concentration as a function of temperature (up to $1823 \mathrm{~K}$ ) on these two characteristics with the aim to increase the chemical and mechanical stability and lead to new substitution strategies and composition considerations. In this context, high- $\mathrm{Y}_{2} \mathrm{O}_{3}$ content doped $\mathrm{HfO}_{2}$ samples (12-33 mol\%) were manufactured to reach a low ionic conductivity and compositions and microstructures were attentively synthesised and analysed to allow comparisons.

\section{Experimental}

\subsection{Sample preparation}

A classical solid state route has been used for the sample synthesis. Yttrium oxide (American Element, purity: 99.99\%, $\mathrm{D}_{50}=0.5-1 \mu \mathrm{m}$ ) was chosen as precursor to form the fluorite solid solution with the hafnium oxide (American Elements, purity: 99.9\%, $\left.\mathrm{D}_{50}<1 \mu \mathrm{m}\right)$. The ionic radii of $\mathrm{Y}^{3+}$ and $\mathrm{Hf}^{4+}$ are respectively 1.019 and $0.83 \AA$ in their corresponding ionic coordination in the fluorite phase (Shannon radii).

After drying at $400 \mathrm{~K}$ overnight, the powders were weighed to obtain the selected rates of $12,14,20$ and 33 mol\% of $\mathrm{Y}_{2} \mathrm{O}_{3}$ in $\mathrm{Y}_{2} \mathrm{O}_{3}$ $\mathrm{HfO}_{2}$ solid solution. The powder mixtures were blended for $4 \mathrm{~h}$ in ethanol in a rotating mixer using stabilised zirconia media. After drying in a rotating evaporator, the blends were sieved $(100 \mu \mathrm{m})$. In the case of high dopant concentration (33 mol\%), the mixed powders were heat treated at $1823 \mathrm{~K}$ during $2 \mathrm{~h}$ in air in order to form the disordered cubic phase of the hafnia solid solution prior to the densification step to minimise the presence of defects such as porosities and composition inhomogeneity. Then, all the powders were isostatically cold pressed at $70 \mathrm{MPa}$ for $2 \mathrm{~min}$ and sintered a first time at $2023 \mathrm{~K}$ for $6 \mathrm{~h}$ in air. A second thermal treatment was performed at $2273 \mathrm{~K}$ in an argon atmosphere in order to reach high densification levels and a similar microstructure between samples, : during $2 \mathrm{~h}$ for low dopant content samples (12 and $14 \mathrm{~mol} \%$ ) and during $4 \mathrm{~h}$ for high dopant content samples (20 and $33 \mathrm{~mol} \%$ ). Afterwards, all the samples were reoxidised in air at $1173 \mathrm{~K}$ during $10 \mathrm{~h}$. A homogeneous whitening of the 
samples was obtained with this last treatment without modifying the grain size. Thus, the contribution of oxygen vacancies due to the thermal treatment under reducing conditions during the synthesis process is eliminated for the characterisation step.

\subsection{Characterisations}

After sintering, density, open porosity (including pores larger than $25 \mathrm{~nm}$ ) and apparent density of pellets were determined by the Archimedes' method using deionised water as immersion medium. X-Ray diffraction (XRD) was performed with an Empyrean PANalytical device in the Bragg-Brentano configuration $(\theta-\theta)$ and using the $C_{u} K_{\alpha}$ radiation. The investigated diffraction range was from $9^{\circ}$ to $90^{\circ}$ with a $0.02^{\circ}$ scanning step. Rietveld refinements were carried out with HighScorePlus software in order to determine lattice parameter as a function of the dopant content.

Densification level was calculated as the ratio of the apparent density to the theoretical density, considering the substitution of $\mathrm{Hf}^{4+}$ cation with $\mathrm{Y}^{3+}$ which brings oxygen deficiency thanks to its lower valence, as expressed in Kröger-Vink notation (Eq. 1) using the Ingel and Lewis formula ${ }^{[46]}$ (Eq. 2).

$$
\begin{aligned}
& \mathrm{Y}_{2} \mathrm{O}_{3} \stackrel{\mathrm{HfO}_{2}}{\rightarrow} 2 \mathrm{Y}_{\mathrm{Hf}}^{\prime}+\mathrm{Vö}+3 \mathrm{O}_{\mathrm{O}}^{\mathrm{X}} \\
& \rho_{\text {Ingel and Lewis }}=\frac{M_{\mathrm{Hf}}+2 M_{\mathrm{O}}+\sum P_{Y} R_{Y_{2} \mathrm{O}_{3}}\left\{\Delta M+\left[\left(P_{\mathrm{O}} / P_{Y}\right)-2\right] M_{O}\right\}}{100+\sum R_{Y_{2} \mathrm{O}_{3}}\left(P_{Y}-1\right)} . \\
& \frac{Z}{10^{-24} \mathrm{Na} a^{3}}
\end{aligned}
$$

Where $M_{H f}, M_{o}$ and $M_{r}$ are the atomic weights of hafnium, oxygen and yttrium $(\mathrm{g} / \mathrm{mol}), \Delta \mathrm{M}$ the difference between the atomic weights of yttrium and hafnium. $P_{Y}$ the number of ions of dopant element per molecule and $P_{O}$ the number of oxygen ions per molecule in yttria. $\mathrm{R}_{2} \mathrm{O}_{3}$ is the molar ratio of $\mathrm{Y}_{2} \mathrm{O}_{3} . N$ is the Avogadro's number, $Z$ the number of molecules per unit cell, and $a$ the cubic lattice parameter $(\AA)$ determined from $X$-Ray diffraction.

After sintering, the average grain size distribution (in number) was assessed by Electron Backscatter Diffraction (EBSD) with a Scanning Electron Microscope (SEM) and a meticulous polishing of the surface $(1 / 4 \mu \mathrm{m})$. Composition and homogeneity of pellets were carefully verified by Inductively Coupled Plasma-Optical Emission Spectroscopy (ICP-OES) (two sets per samples and five measurements per set) and by Energy Dispersive X-ray Spectroscopy (EDS) with pure reference samples of $\mathrm{HfO}_{2}$ and $\mathrm{Y}_{2} \mathrm{O}_{3}$ (five spectra per sample with scanning surface of $100 \times 100 \mu \mathrm{m}^{2}$ ).

The average linear Thermal Expansion Coefficient (TEC) was determined under air flow ( $20 \mathrm{~mL} / \mathrm{min}$ ) from 473 to $1823 \mathrm{~K}$ with a heating rate of $5 \mathrm{k} / \mathrm{min}$ using a high-temperature dilatometer (SETARAM, SETSYS Evolution) over three cycles of heating and cooling. Parallelepipedic ceramic sample dimensions were approximately $5 \times 5 \mathrm{~mm}^{2}$ and $10 \mathrm{~mm}$ in length.

Electrochemical Impedance Spectroscopy (EIS) measurements were carried out on pellets of $1 \mathrm{~mm}$ thickness and $15 \mathrm{~mm}$ diameter (machined from sintered materials) by employing an alternative current two-probe method with a signal amplitude between 10 and $200 \mathrm{mV}$ in the frequency range $1 \mathrm{~Hz}-1 \mathrm{MHz}$. Before the conductivity measurement, the discs were painted with a platinum ink and then fired at $1073 \mathrm{~K}$ for $10 \mathrm{~h}$ to ensure a good bond between the sample surfaces and the electrodes. All these characterisations were performed under steady-state conditions in ambient air $\left(\mathrm{PO}_{2}=21.3 \mathrm{kPa}\right)$ and over one cycle of heating and cooling between 600 and $1150 \mathrm{~K}$.

\section{Results and discussion}

\subsection{Microstructure and composition}

Regardless of the substitution ratio, the XRD patterns of all samples can be indexed with Fm-3 m space group cubic structure with published data of a non-doped $\mathrm{HfO}_{2}$ ideal cubic phase (JCPDS no. 00-053-0560) and a disordered cubic phase called fluorite of following composition $\mathrm{Hf}_{2} \mathrm{Y}_{2} \mathrm{O}_{7}$ (JPDS no. 00-024-1406) (Fig. 1). As expected, neither monoclinic nor tetragonal phases are detected. This feature is positive, since the presence of monoclinic phase could induce a contraction or an expansion of the cell due to the monoclinic-tetragonal allotropic transformation. Also, the metastable tetragonal phase could decompose into a lowcontent yttria tetragonal phase and a high-content yttria cubic phase leading to inhomogeneous compositions of the ceramic samples. Both of these phases are thus considered as non-welcome impurities in desired high temperature stable samples. These XRD data confirm the total stabilisation of all the solid solution compositions in a cubic disordered phase, which is a mandatory result to start the property characterisation stage. 
At high angle, according to XRD patterns reported in Fig. 1, it can be noticed that samples peaks show a shift to the low angles compared to non-doped cubic solid solution and a shift to the high angle compared to the high-content doped cubic solid solution. The impact of the yttria content on the lattice parameter was quantified by Rietveld refinement. For an accurate analysis, the lattice parameter was implemented in the corresponding crystallographic structure to generate with VESTA software diffraction patterns then used as reference patterns.

An empirical criteria allowing to the formation of a pyrochlore-type phase has been proposed in the literature: $\mathrm{r}^{3+}{ }_{\mathrm{RE}} / \mathrm{r}^{4+} \mathrm{Hf}>1.46^{[47-}$ ${ }^{49]}$. In the case of the $\mathrm{Y}_{2} \mathrm{O}_{3}-\mathrm{HfO}_{2}$ system, this ratio is equivalent to 1.23 . Thus, the non-existence of the pyrochlore phase in the studied system ${ }^{[13,14,50,51]}$ and the conservation of a disordered cubic fluorite phase is confirmed.

From Rietveld analysis, all the lattice parameters of the solid solution were determined and it was found that an increase in the substitution of $\mathrm{Hf}^{4+}$ by $\mathrm{Y}^{3+}$ leads to a rise in the lattice parameter (Fig. 2).

A linear regression on measured lattice parameters demonstrates that Vegard's type law is applicable (Eq. 3).

$$
a=0.0029 \times x+5.0946 \text { with } \Delta a=0.0004
$$

Where $a$ is the lattice parameter $(\AA)$, $x$ the molar dopant content (\%), 0.0029 a constant depending on dopant species, and 5.0946 the lattice parameter of the cubic hafnia without dopant.

Furthermore, the predicted lattice parameter for a dopant content of zero by linear regression corresponds to the lattice parameter of the JCPD file for the cubic non-doped hafnia $(a=5.095 \AA$ ). These data are perfectly correlated with other literature values ${ }^{[14]}$.

The theoretical density was calculated by using the lattice parameters determined with the Rietveld analysis (Table 1). By comparing the measured apparent density of the samples with the calculated theoretical density, it has been validated that fully dense samples were obtained ( $>97 \%)$. At least, these samples do not show an opened porosity thus avoiding the introduction of a short-circuit of diffusion under a molecular state. Densification level has to be cautiously checked as porosity may have an incidence on the conductivity measurements (increasing the grain boundary contribution induces a lower oxygen mobility ${ }^{[30]}$ ). High-density levels are also confirmed with SEM micrographs (Fig. 3).Other microstructural property like grain size have an impact on the ionic conductivity measurement ${ }^{[52]}$. Since it allows taking into account a large amount of grains, the high spatial resolution of the EBSD technique has been used to analyse the grain size diameter distribution in number. To further process these results, Orientation Imaging Microscopy Analysis ${ }^{\mathrm{TM}}$ software was used to run grain size distribution characterisation and several filters were applied on data. First, grains located at the edge of the picture were excluded. Then, each grain was modelled as a circle. Thus, on the EBSD maps of $\mathrm{Y}_{2} \mathrm{O}_{3}$ doped $\mathrm{HfO}_{2}$ microstructures presented in Fig. 3, sizes of the analysed domains as a function of $\mathrm{Y}_{2} \mathrm{O}_{3}$ amount are visible (mean particle size reported in Table 1). Finally, after fitting the thermal treatment for each composition, all the samples exhibit an equivalent mean grain size (in number) ranging from 14 to $19 \mu \mathrm{m}$.

Finally, the exact elementary composition of each sample was double-checked using ICP-OES and EDX Spectroscopy techniques. From results reported in Table 2, it can be seen that both weight element contents measured by ICP and EDX techniques are in line with the theoretical values. The wider difference observed between theoretical values and ICP measurements could be due to the difficulty to perfectly dissolve the Hf1-xYxO2 compounds in acid.

Characterisations of microstructures and compositions confirm that thermal expansion behaviour and ionic conductivity measurements were done on fully dense samples of pure fluorite of $\mathrm{Y}_{2} \mathrm{O}_{3}-\mathrm{HfO}_{2}$ solid solution with similar grain sizes and targeted compositions.

\subsection{Thermal expansion coefficient behaviour}

In this part, the influence of high dopant content on the thermal expansion of Yttria Stabilised Hafnia (YSH) is studied.

All the studied materials are polycrystalline ceramics and have a cubic symmetry, thus the thermal expansion coefficient could be considered identical in all the directions. Moreover, at this level of dopant concentration, samples contain vacancies and associated vacancies which have an impact on cations neighbourhood and finally on the binding energy. In this study, all these defects are supposed to be randomly distributed. The measurement of the thermal expansion is considered as an average of all these contributions. Results are reported in Fig. 4. 
As shown in Fig. 4 for all the compositions, the thermal expansion as a function of the temperature between heating and cooling curves do not present significant differences (no structural evolution was expected since the sintering temperature is much higher, $2023 \mathrm{~K}$ ). All the curves are overlapped and present a slight curvature. The thermal behaviour of YSH samples during a heating up to $1873 \mathrm{~K}$ is similar to the one described in the literature. Indeed, the higher the temperature, the higher the expansion. Considering a linear thermal expansion, the maximum is included between 1.65 and $1.71 \%$ for the studied compositions. The $14 \mathrm{~mol} \%$ doped sample has the largest thermal expansion whereas the $33 \mathrm{~mol} \%$ one has the lowest.

As explained by Sameshima et al. ${ }^{[53]}$, the non-linear behaviour of the thermal expansion as a function of the temperature shown in Fig. 4 could be explained by the potential curve based on the lattice energy theory. The potential energy between cation and anion is expressed as followed:

$$
E=-\frac{A N_{A} Z_{1} Z_{2} e^{2}}{4 \pi \varepsilon_{0} r}+\frac{B}{r^{n}}
$$

Where $r$ is the inter-ionic distance $(\mathrm{m}), A$ the Madelung constant of 2.51939 for the fluorite structure, $N_{A}$ the Avogadro's number $6.022 .10^{[23]} \mathrm{mol}^{-1}, Z_{1}$ the average cation valence which depends on the doping rate (respectively 3.786, 3.754, 3.663, 3.500 for the selected composition), $Z_{2}$ the average anion valence including oxygen vacancy $(1.893,1.877,1.834,1.750$ for the selected composition), $e$ the charge of the electron $1.60210^{-19} \mathrm{C}, B$ the repulsion coefficient (depending on the distance of the cationoxygen bond), $n$ the Born exponent ( 12 for $\mathrm{Hf}^{4+}$ and $\mathrm{Y}^{3+}, 7$ for $\mathrm{O}^{2-}$, giving $(12+7) / 2=9.5$ ), and $\varepsilon_{0}$ the vacuum permittivity 8.854 $10^{-12} \mathrm{~F} / \mathrm{m}$. Indeed, Sameshima et al. ${ }^{[53]}$ has explained the non-linearity of the thermal expansion with the anharmonicity of the potential energy when the temperature increases.

The linear approximation done to calculate the average Thermal Expansion Coefficients (500-1830 K) is very close to the one obtained by a polynomial fit ${ }^{[53]}$. Thus, to obtain the following thermal expansion coefficients, linear fits were performed, and the slopes taken from these fits lead to the values reported in the Fig. 5. First, from 12 to 14 mol\% $\mathrm{Y}_{2} \mathrm{O}_{3}$, the TEC increases slightly and then, from 14 to 33 mol\% a progressive decrease is observed.

The TEC values of low content dopant samples are comparable with the range of values found by Li et al. on samples containing up to 10 mol\% of $\mathrm{Y}_{2} \mathrm{O}_{3}{ }^{\left[{ }^{[5]}\right.}$. Nevertheless, at higher dopant ratio, the trend is surprising considering the ionic radius of the doping element $\left(\mathrm{Y}^{3+}, 1.019 \AA\right)$ being higher than the host cation one $\left(\mathrm{Hf}^{4+}, 0.83 \AA\right.$ ). Indeed, the cubic stabilisation of the hafnia is achieved by substituting hafnium cations by yttrium ones. However, this substitution initially leads to an increase in the thermal expansion linked to the weaker atomic bonding between atoms ${ }^{[54-56]}$ (Table 3). Indeed, literature studies generally conclude that an increase in dopant concentration correlated with the rise of the oxygen vacancies leads to a lower binding energy, and thus, to a rise in the thermal expansion coefficient. But generally, studies consider moderate dopant contents (up to $10 \mathrm{~mol}_{\%} \mathrm{RE}_{2} \mathrm{O}_{3}$ ) equally for gadolinium oxide in ceria or yttrium oxide in hafnia ${ }^{[36]}$.

However, start from a certain amount of dopant, experimental data demonstrate a decrease of the thermal expansion coefficient. This phenomenon is explained by two competing processes correlated to the high yttrium content leading to high oxygen vacancies and larger ionic radius.

Indeed, the chemical expansion comes firstly from the formation of vacancies and, secondly, from the increase of the cation radius induced by the substitution of the host cation by a larger radius dopant cation. By considering oxygen vacancy as independent defects, Marrocchelli et al. ${ }^{[29,58]}$ studied both experimentally and computationally the factors responsible for defect-induced chemical expansion found in fluorite structures. The formation of vacancies implies electrostatic interactions. Indeed, by removing an oxygen ion, the cation electrostatic repulsion is not screened and thus relaxed away from the vacancy, allowing other anions to get closer to it. Locally, these distortions lead to a contraction of the lattice. Taking into account different computational methods, as Molecular Dynamics or Density Functional Theory, some authors have shown that electrostatic interactions may dominate around oxygen vacancies unlike steric ones ${ }^{[59,60]}$. In the hafnia lattice it was calculated from experimental data that the formation of an oxygen vacancy leads to a vacancy radius of approximatively $0.87 \AA^{[29]}$ largely lower than the oxygen ionic radius and the dopant radius.

The impact of the defect complexes on the expansion has also been studied. Bishop et al. ${ }^{[61]}$ have demonstrated that defect complexes on doped ceria are formed to neutralise local electrostatic charges and can be described as isolated defects.

Thus, studies seem to conclude that when the dopant content continuously increases, an increase in the thermal expansion is first observed due to the decrease of the bond strength (steric effect), then, a maximum is reached before a strong decrease, due to the high amount of oxygen vacancies leading to the lattice contraction. Indeed, highly doped solid solutions hold extensive 
possibility of the surrounding environment hence numerous defect complexes causing more contractions of the lattice, which ultimately leads to a decrease in the thermal expansion coefficient ${ }^{[41,62,63]}$.

\subsection{Ionic conductivity}

The influence of dopant content within the $\mathrm{HfO}_{2}-\mathrm{Y}_{2} \mathrm{O}_{3}$ solid solution has been studied on the oxygen ion conductivity. The main objective is to lower the oxygen diffusion through the ceramic. The two probes EIS measurement is an easy method to characterise oxygen ion conductivity for different compositions. It can be mentioned that the electronic contribution is negligible in the studied domain of oxygen partial pressure and temperature ${ }^{[43,64]}$. Indeed, none of the compounds have contribution of electronic conductivity since there are no electrons free in this stabilised state. Hafnium and Yttrium cations cannot be more oxidised or reduced as they both only have one valency state, respectively (+IV) and (+III). Moreover, yttria stabilised hafnia exhibits a larger stability range under different oxygen partial pressures and temperatures compared to YSZ ${ }^{[43]}$.

Ionic conductivity $\left(\sigma_{i}\right)$ can be linked to the oxygen diffusion coefficient determined by oxygen isotopic diffusion measurement using the Nernst-Einstein equation (Eq. 5).

$$
\sigma_{i}=\frac{z_{i}^{2} F^{2}}{k T} f C_{i} D_{i}
$$

with $\sigma_{i}$ the ionic conductivity $(\mathrm{S} / \mathrm{cm}), z_{i}^{2} \mathrm{~F}^{2}$ the molar electric charge of the ionic carrier $i, D_{i}$ the self-diffusion coefficient $\left(\mathrm{cm}^{2} / \mathrm{s}\right), C_{i}$ the charge carriers number per $\mathrm{cm}^{3}, k$ the Boltzmann constant $(\mathrm{J} / \mathrm{K}), T$ the absolute temperature $(\mathrm{K})$ and $f$ the correlation factor defining the efficiency between two consecutive jumps (depending on the isotropic character of the structure). The diffusion coefficient determined from conductivity measurements could be related to the tracer diffusion coefficient $D^{*}$ with the following equation (Eq. 6).

$$
D^{*}=H_{R} D_{i}
$$

where $H_{R}$ is the Haven ratio. In the case of single ions and random jump, $H_{R}$ could be equal to 1 . When there is movement of other charge carriers or electrons, $H_{R}<1$. When other defects like vacancy pairs or impurity-vacancy pairs participate to diffusion which is not seen in conductivity, $H_{R}>1^{[31,42,64,65]}$. Thus, in the case where diffusion of oxygen ion is done by only one type of defect (free mobile vacancy), the diffusion coefficient from conductivity is equal to the migration coefficient and proportional to the concentration of vacancies.

The response of a sample to a sinusoidal alternative current with variable frequency generally leads to describe the sample as the parallel association of a Resistance and a Capacitance in which RC components correspond to the contribution from the bulk, grain boundaries and electrode/sample interface. A least square fit of an equivalent circuit based on parallel Constant Phase Elements $(C P E)$ and a resistance (R) was obtained for each measurement using the following impedance (Z) function.

$$
|Z|=\frac{R}{\sqrt{1+(\omega R C)^{2}}}
$$

where $Z$ is the impedance $(\Omega), R$ the resistance $(\Omega), C$ the associated capacitive effect $(F)$ and $\omega$ the resonance angular frequency $\left(\mathrm{s}^{-1}\right)$.

The evolution of the complex impedance diagram as a function of the applied frequency and the model of the equivalent are plotted on the Nyquist representation in Fig. 6. Only two semi-circles are clearly detected for all the elaborated yttria-doped hafnia samples.

The green curve at high frequency on the left of the graph is assigned to the bulk resistivity. The red one in the low frequency range is typical of the Pt electrode response. The nature of the samples and the high-density level of the ceramic samples could be the two explanations of the absence of semi-circles related to the grain boundary. Indeed, fully dense samples do not show any grain boundary blocking effect. Moreover, a homogeneous composition in the ceramic will lead to the same activation energy for the bulk and the grain boundary and thence to a convolved curve. It is also possible that grain boundaries bring such a low resistivity that they are not noticeable ${ }^{[66]}$ in testing conditions,. None of these hypotheses have been further analysed since the 
first purpose of the study is to assess the impact of the composition on the ionic conductivity and to confirm the measurement of bulk resistance. The capacitance of all samples has been checked. Typical results are reported on Fig. 7 for 12 mol\% $\mathrm{Y}_{2} \mathrm{O}_{3}$.

The observed capacitance from the Fig. 7 is in good agreement with literature data at bulk capacity within the range of $10^{-11}$ to $10^{-} 10 \mathrm{~F}$ and capacitance of the polarisation of the electrode $10^{-4}$ to $10^{-6} \mathrm{~F}$ (for Pt electrodes under air). The capacitance corresponding to the grain boundary contribution is generally observed around $10^{-8} \mathrm{~F}$ and does not appear in the studied samples ${ }^{[64,67]}$. As all the samples show the same capacitance tendencies, it means that they have the same dielectric constant and thus, the same microstructure.

Then, for conductivity calculation, the bulk resistance of the sample is read at the intersection of the modelled semi-circles with the real axis at high frequency. The conductivity is then deduced using (Eq. 8).

$$
\sigma=\frac{l}{R A}
$$

where $I$ is the thickness $(\mathrm{cm}), R$ the resistance $(\Omega)$ and $A$ the surface area $\left(\mathrm{cm}^{2}\right)$ of the samples, $I / A$ gives the geometrical factor.

Regardless of the composition, the evolution of ionic conductivity as a function of the temperature is similar during heating and cooling measurements (Fig. 8). This demonstrates that the samples do not suffer of microstructure or phase instability as proven earlier when applying thermal treatment during process and associating X-Ray patterns analysis. Generally, doped-hafnia samples show a lower ionic conductivity than the most currently employed $8 \mathrm{YSZ}$ material $\left(\mathrm{Zr}_{0.852} \mathrm{Y}_{0.148} \mathrm{O}_{1.926}\right)$ in fuel cell or thermal barrier fields ${ }^{[31,43,65,68]}$ as presented in Fig. 8. Moreover, the increase in the dopant content leads to lower the ionic oxygen conductivity. As shown in Fig. 8, and more precisely in Fig. 9, when the dopant content increases, the ionic conductivity decreases at both low and high temperatures (respectively 673 and $1173 \mathrm{~K}$ ).

According to these results, the decrease of the ionic conductivity difference between the lowest and the highest dopant content is more than two decades at low temperature whereas it is around one decade at high temperature. A linear dependence on the dopant content can be observed at high temperature whereas other contributions must be taken into account at the lowest temperature. Finally, it has been demonstrated that 33 mol\% of $\mathrm{Y}_{2} \mathrm{O}_{3}$ provide the lowest conductivity, correlating with the work of Strickler et al. ${ }^{[69]}$ and Burbano et al. ${ }^{[70]}$. The data values also seem to fulfil the Van Gool criterion. Indeed, the concentration of oxygen vacancy is lower for low dopant content and the ionic conductivity is higher than the high dopant content samples. Indeed, a high dopant content meaning a high oxygen vacancy concentration induces numerous neighbourhood configurations with a high degree of possibility for first, second, and third neighbour leading to multiple interaction possibilities. Finally, from Van Gool criterion, the increase of neighbourhood configuration is associated with numerous possibilities of vacancy sites with different energies, decreasing the diffusion of oxygen which prefers sites with very similar energy to diffuse ${ }^{[36]}$.

Moreover, several types of defects associations exist, from the simplest $\left\{\mathrm{Y}_{\mathrm{Hf}}-\mathrm{V}_{\mathrm{O}}\right\}^{\circ}$ at low dopant concentration over a long range ordering through vacancy pairs up to the formation of a new phase at a high enough degree of substitution ${ }^{[36]}$. These associations do not participate to the oxygen ion conductivity and have an impact on the diffusion, which could be illustrated through analysis of the activation energy.

Ionic conductivity is thermally activated and generally follows a linear Arrhenius type law ${ }^{[71]}$ :

$$
\sigma=\frac{A}{T} e^{\frac{-E_{a}}{K_{B} T}}
$$

where $A$ is the preexponential factor $(\mathrm{SK} / \mathrm{cm})$, which contain information dependent on the microscopic characteristics, $E_{a}$ denotes the activation energy for the conduction process $(\mathrm{eV}), k$ is is the Boltzmann constant $(\mathrm{eV} / \mathrm{K})$, and $T$ is the absolute temperature value $(\mathrm{K})$.

An accurate analysis of the Arrhenius plots (Fig. 10) shows a small slope change around $873 \mathrm{~K}$ for low dopant concentrations (12 and $14 \mathrm{~mol} \%$ ), and a linear behaviour at high dopant concentrations ( $20 \mathrm{~mol} \%$ and $33 \mathrm{~mol} \%$ ). The non-linear behaviour along the range of temperature could be due to the presence of defects associations at low temperature and their dissociation above this temperature. This curvature has also been reported by different authors in the zirconia based materials at various others temperatures 723,873 or even at $1123 \mathrm{~K}^{[12,72-74]}$. Confirmed by oxygen tracer self-diffusion measurements, many vacancies are free and mobile above $773 \mathrm{~K}$ for YSZ samples ${ }^{[31]}$, whereas defects are interacting strongly at lower temperatures. Thus, the rupture 
of the curve's linearity can be explained by the total activation energy being the sum of the enthalpy of association needed to dissociate defect pairs and the migration enthalpy of an isolated oxygen vacancy. The enthalpy of association is then linked to the strain energies developed in a structure with strong ionic radii mismatch and high dopant content. This approach has been well studied by several authors with different samples compositions ${ }^{[35,65,66,74-76]}$.

The Arrhenius curves of all samples have been plotted in Fig. 10(a) and show activation energy for conduction process between 600 and $1150 \mathrm{~K}$. Activation energies calculated for selected compositions are much higher than for 8YSZ. Indeed, the activation energy for the conduction process of $8 \mathrm{YSZ}$ is generally comprised around $0.8 \mathrm{eV}$ and up to $1.4 \mathrm{eV}$ for $35 \mathrm{~mol}^{2}$ of $\mathrm{Y}_{2} \mathrm{O}_{3}{ }^{[77,78]}$, besides, YSH samples have activation energy comprised between $1.17 \mathrm{eV}$ and $1.42 \mathrm{eV}$. Indeed, as an example, the value for the $14 \mathrm{~mol} \%$ $\mathrm{Y}_{2} \mathrm{O}_{3}$ sample perfectly matches the one from Trubelja ${ }^{[12]}$ of $1.3 \mathrm{eV}$ and our measured value of $1.26 \mathrm{eV}$. Previous study which reported that a maximum of ionic conductivity corresponds to a minimum of the activation energy ${ }^{[12]}$ also comforts the results from our composition range for 12 mol\% having the highest ionic conductivity and the lowest activation energy. However the opposite does not seem to be true as the lowest activation energy is reached for the 20 mol\% sample which ionic conductivity values stand between those of $14 \mathrm{~mol} \%$ and $33 \mathrm{~mol} \%$.

Thus two different activation energies have been calculated considering the transition temperature of $870 \mathrm{~K}$ shown in Fig. $10(\mathrm{~b})$ and (c) and in Table 4.

From this data, it seems that dopant concentration has no influence on the activation energy at low temperature. Indeed, the standard deviation between activation energy values is around $0.08 \mathrm{eV}$, whereas it reaches $0.19 \mathrm{eV}$ at high temperature. This difference at high temperature could be explained by the difference of dissociation state of samples. Indeed, the low dopant content samples showing a non-linear Arrhenius behaviour have presumably reach their dissociation/disorder state, allowing to determine association and migration contribution (Table 4) ${ }^{[71]}$. At the same time, the linear behaviour of highest dopant concentration indicates that they still have an ordered structure above $1200 \mathrm{~K}$. Thus it could mean that high dopant concentrations have stronger defect interactions.

This interpretation is generally used to identify the behaviour of relatively low dopant content defect-fluorite and with an approximate temperature of association/dissociation phenomenon considering linear slope changes. Lately, a new model has been developed by Ahamer et al. ${ }^{[68]}$ to study dopant concentration of 8-12 mol\% based on a two barriers model which is more comprehensive than the associate model.

Independently from an association-dissociation state and migration temperature transition, the two barrier model considers all the vacancies as mobile, moving around in a complex energy landscape with jumps varying spatially and temporarily and subject to multiple interactions (vacancy-vacancy and vacancy-dopant). This model leads to the following analytical equation (Eq. 10).

$$
\sigma T=\left(\frac{1}{\gamma_{1} e^{-E_{a, 1 / k T}}}+\frac{1}{\gamma_{2} e^{-E_{a, 2 / k T}}}\right)^{-1}
$$

where $E_{a, 1}$ and $E_{a, 2}$ are the two barrier heights $(e V)$, respectively for high and low temperatures, $k$ is Boltzmann constant $(\mathrm{J} / \mathrm{K})$ and $\gamma_{i}$ the following ratio:

$$
\gamma_{i}=\frac{z^{2} e_{0}^{2} a_{0}^{2} n_{v, t o t} v_{i}^{0}}{k \beta_{i}}
$$

where $z$ denotes the absolute charge, eo the elementary charge $(C)$, ao the average jump distance $(m), n_{v, t o t}$ the total vacancy concentration $\left(\mathrm{m}^{-3}\right), \mathrm{v}_{\mathrm{i}}^{0}$ is a pre-factor of the jump frequency (including the attempt frequency jump, migration entropy and correlation effects) $\left(\mathrm{s}^{-1}\right), \mathrm{k}$ is Boltzmann constant $(\mathrm{J} / \mathrm{K})$ and $\beta_{i}$ is a weight factor of successful jumps across barrier heights $E_{a, i}$.

The two barriers models fit very well with the experimental data besides the fact that samples contain substitution of $\mathrm{Hf}$ atoms by $Y$ atoms between 21.4 and $50 \%$. Thus the landscape energy could be simplified with two main barrier types representing two average vacancy paths even for highly dopant content samples.

Thus, as explained by the author of the analytical equation, $E_{a, 1}$ determines the energy barrier height for the high temperature range and $E_{a, 2}$ for the low temperature range. In Table 5, the four fitting parameters seem to highly depend on dopant concentration and temperature range. 
Indeed, the corresponding barrier heights depend on the dopant concentration at both low and high temperature and this effect is slightly more pronounced for the lower barrier which determines the high temperature range $\left(E_{a, 1}\right)$. The low energy barriers are comprised between 0.64 and $1.4 \mathrm{eV}$ with a minimum for dopant content of $\mathrm{Y}-14$ and a maximum of energy for $\mathrm{Y}-20$. At low temperature, high energy barriers are contained in a narrow range of values between 1.40 and $1.60 \mathrm{eV}$. Thus, the increase of the doping concentration has a much stronger effect at high temperatures at high dopant content compared to 8-12 mol\% of yttria stabilised zirconia ${ }^{[68]}$. The two factors $\gamma_{1}$ and $\gamma_{2}$ do not show linear trend as observed during the study with relatively low dopant content. This makes the interpretation of theses parameters more difficult as their evolution could be due to $\beta$ or $v_{i}{ }^{\circ}$ contributions. However, for almost all the samples, $\gamma_{1}$ is at least two orders of magnitude smaller than $\gamma_{2}$ except for the $Y-20$. Indeed, on the case of 20 mol\% dopant content, the $\gamma$ values are very close, as the energy heights without net plotting bending in the $\sigma \mathrm{T}-\mathrm{T}^{-1}$ curves (Fig. 11). Thus, for this sample in this range of temperature and according to the interpretation of the barrier model where the average vacancy path encounters one single value average barrier height, it could be mean. It is reinforced by the lowest value of $\nu_{2} / \gamma_{1}$ ratio suggesting that there are few low barriers passed compared to high barriers in an average sequence of successful vacancy jumps.

Also, to explain the difference observed for high dopant content samples, other models have to be considered. Indeed, the $20 \mathrm{~mol} \%$ corresponding to the substitution of a third of hafnium by yttrium seems to have strong defect association interactions based on both model (association/dissociation and two barriers model), only one value of activation energy is found for the range of temperature. While for a half of substitution ( $33 \mathrm{~mol} \%$ of dopant), two energy barriers have been found, meaning that some disorder have been brought in the structure in the range of temperature. However, it shows the smallest ionic conductivity. This low value could be explained by the highest rate of substitution of $\mathrm{Hf}$ by $\mathrm{Y}$. Indeed, the increase in dopant content implies more tetrahedron composed with $\mathrm{Y}^{3+}$ instead of $\mathrm{Hf}^{4+}$ and therefore more $\mathrm{Hf}-\mathrm{Y}$ and $\mathrm{Y}-\mathrm{Y}$ barriers instead of $\mathrm{Hf}-\mathrm{Hf}$. It is well known for zirconia that $\mathrm{Zr}-\mathrm{Zr}$ is a lower barrier $(0.5 \mathrm{eV})$ than $\mathrm{Y}-\mathrm{Zr}(0.9-1.3 \mathrm{eV})$ and $\mathrm{Y}-\mathrm{Y}(1.3-2.0 \mathrm{eV}){ }^{[79]}$ while same order of magnitude is verified for $\mathrm{Hf}{ }^{[44]}$. This will lead to a limitation of the diffusion of oxygen through the structure and a minimisation of ionic conductivity.

Finally, even if it is not the highest content of yttrium, it seems that the $Y-20$ composition, brings the strongest interactions through high activation energy. This anomaly could come from particular alignments of ordered vacancies or result from the matching amount promoting correlated jumps or even deep trap blocking sites ${ }^{[80]}$.

\section{Conclusion}

To synthesise, the influence of the dopant content on thermal expansion and ionic conductivity has been studied on four dense and targeted hafnia-based compositions samples with high $\mathrm{Y}_{2} \mathrm{O}_{3}$ content from 12 to $33 \mathrm{~mol} \%$. Indeed, all the samples have been extensively analysed to confirm the fluorite-type hafnia phase stabilisation and the related grain size equivalence. This work has demonstrated that thermal expansion and ionic conductivity at high temperature are both strongly correlated to the amount of dopant incorporated and thus to the oxygen vacancies content.

More precisely, it has been found that despite the increase of the disordered cubic fluorite phase in the lattice parameter from 5.13 to $5.19 \AA(1.2 \%)$ with the increase in the dopant content, the thermal expansion coefficient remains constant in the range of $1110^{-6} / \mathrm{K}$ and even decreases from 11.26 to $10.8810^{-6} / \mathrm{K}(-3.3 \%)$. Indeed, the steric effect of dopants with larger ionic radius was minor compared to the effect of oxygen vacancies which could be free or associated as long as they scatter coulombic interaction and promote lattice contraction. The ionic conductivity depends on the state of defect association and their ordering. The ionic conductivity is reduced by two decades when increasing the substitution from 21.4 to $50 \%$. Using several models, the trend of the ionic conductivity has been explained and an interpretation for the maximum value of the activation energy observed for the sample with 20 mol\% of $\mathrm{Y}_{2} \mathrm{O}_{3}$ as well as for the low ionic conductivity for 33 mol\% of $\mathrm{Y}_{2} \mathrm{O}_{3}$ has been proposed.

Finally, considering these results, it could be interesting to further investigate higher dopant contents which could bring same thermal expansion and lower ionic conductivity without neglecting the melting temperature of the formed cubic solid solution.

Declaration of competing interest: The authors declare that they have no known competing financial interests or personal relationships that could have appeared to influence the work reported in this paper.

Acknowledgement: The authors would like to thank Claire Sanchez (ONERA) for X-ray diffraction, N. Horezan (ONERA) for the EBSD analysis and S. Fourcade (CNRS, ICMCB) for his kind and efficient assistance on ionic conductivity measurements. This work was partially funded by CNES. 


\section{References}

1. D. Zhu, et al. Advanced Environmental Barrier Coating Development for SiC-SiC Ceramic Matrix Composite Components. https://ntrs.nasa.gov/search.jsp?R=20170009570 (2017)

2. X.Q. Cao, R. Vassen, D. Stoever. Ceramic materials for thermal barrier coatings. J. Eur. Ceram. Soc., 24 (2004), pp. 1-10.

3. Y. Song, et al. Effect of geometric parameter on thermal stress generation in fabrication process of double-ceramic-layers thermal barrier coating system. J. Eur. Ceram. Soc., 38 (2018), pp. 3962-3973.

4. Jackson Poerschke, Levi. Silicate deposit degradation of engineered coatings in gas turbines: progress toward models and materials solutions. Annu. Rev. Mater. Res., 47 (2017), pp. 297-330.

5. N. Pelletier, J.-Y. Lestrade. Overview of the CNES "high Performance Green Monopropellant Project": Requirements, Organization \& Breakthroughs. In Space Propulsion 2018. (2018)

6. Arthur J. Fortini. Combustion Chambers for Advanced Monopropellant Engines | Joint Propulsion Conferences (2003), $10.2514 / 6.2003-4730$.

7. K. Upadhya, J.M. Yang, W. Hoffman. Advanced Materials for Ultrahigh Temperature Structural Applications Above 2000 Deg C. https://apps.dtic.mil/docs/citations/ADA397998 (1997)

8. D. Zhu. Hafnia-Based Materials Developed for Advanced Thermal/Environmental Barrier Coating Applications. https://ntrs.nasa.gov/search.jsp?R=20050192261 (2004)

9. R.P. Haggerty, P. Sarin, Z.D. Apostolov, P.E. Driemeyer, W.M. Kriven. Thermal expansion of $\mathrm{HfO}_{2}$ and $\mathrm{ZrO}_{2}$. J. Am. Ceram. Soc., 97 (2014), pp. 2213-2222.

10. S. Stecura, W.J. Campbell. United States \& Bureau of Mines. Thermal Expansion and Phase Inversion of Rare-earth Oxide. U.S. Department of the Interior, Bureau of Mines (1961)

11. J. Wang, H.P. Li, R. Stevens. Hafnia and hafnia-toughened ceramics. J. Mater. Sci., 27 (1992), pp. 5397-5430.

12. M.F. Trubelja, V.S. Stubican. Ionic conductivity of the fluorite-type Hafnia- $\mathrm{R}_{2} \mathrm{O}_{3}$ Solid solutions. J. Am. Ceram. Soc., 74 (1991), pp. 2489-2494.

13. E.R. Andrievskaya. Phase equilibria in the refractory oxide systems of zirconia, hafnia and yttria with rare-earth oxides. J. Eur. Ceram. Soc., 28 (2008), pp. 2363-2388.

14. D.W. Stacy, D.R. Wilder. The yttria-hafnia system. J. Am. Ceram. Soc., 58 (1975), pp. 285-288.

15. A. Kulkarni, et al. Comprehensive microstructural characterization and predictive property modeling of plasma-sprayed zirconia coatings. Acta Mater., 51 (2003), pp. 2457-2475.

16. R. Vaßen, M.O. Jarligo, T. Steinke, D.E. Mack, D. Stöver. Overview on advanced thermal barrier coatings. Surf. Coat. Technol., 205 (2010), pp. 938-942.

17. Y. Zhao, et al. Thermal aging behavior of axial suspension plasma-sprayed yttria-stabilized zirconia (YSZ) thermal barrier coatings. J. Therm. Spray Technol., 24 (2015), pp. 338-347.

18. B. Saruhan, P. Francois, K. Fritscher, U. Schulz. EB-PVD processing of pyrochlore-structured La2Zr2O7-based TBCs. Surf. Coat. Technol., 182 (2004), pp. 175-183.

19. R. Vaßen, F. Traeger, D. Stöver. New thermal barrier coatings based on Pyrochlore/YSZ double-layer systems. Int. J. Appl. Ceram. Technol., 1 (2004), pp. 351-361.

20. J.W. Fergus. Zirconia and pyrochlore oxides for thermal barrier coatings in gas turbine engines. Metall. Mater. Trans. E, 1 (2014), pp. 118-131.

21. U. Schulz, A. Nowotnik, S. Kunkel, G. ReiterEffect of processing and interface on the durability of single and bilayer 7YSZ / gadolinium zirconate EB-PVD thermal barrier coatings. Surf. Coat. Technol., 381 (2020).

22. J.J. Gomez Chavez, et al. Effects of yttria content on the CMAS infiltration resistance of yttria stabilized thermal barrier coatings system. J. Mater. Sci. Technol., 43 (2020), pp. 74-83.

23. S. Mahade, N. Curry, S. Björklund, N. Markocsan, P. Nylén. Failure analysis of Gd2Zr2O7/YSZ multi-layered thermal barrier coatings subjected to thermal cyclic fatigue. J. Alloys. Compd., 689 (2016), pp. 1011-1019.

24. J.A. Ruud, A. Bartz, M.P. Borom, C.A. Johnson. Strength degradation and failure mechanisms of electron-beam physical-vapordeposited thermal barrier coatings. J. Am. Ceram. Soc., 84 (2001), pp. 1545-1552.

25. K. Matsumoto, Y. Itoh, T. Kameda. EB-PVD process and thermal properties of hafnia-based thermal barrier coating. Sci. Technol. Adv. Mater., 4 (2003), pp. 153-158.

26. P. Duran, C. PascualPhase equilibria and ordering in the system $\mathrm{HfO}_{2}-\mathrm{Yb}_{2} \mathrm{O}_{3}$. J. Mater. Sci., 19 (1984), pp. $1178-1184$.

27. H. Hayashi, et al. Thermal expansion coefficient of yttria stabilized zirconia for various yttria contents. Solid State lon., 176 (2005), pp. 613-619.

28. H. Hayashi, et al. Thermal expansion of Gd-doped ceria and reduced ceria. Solid State lon., 132 (2000), pp. $227-233$.

29. D. Marrocchelli, S.R. Bishop, J. Kilner. Chemical expansion and its dependence on the host cation radius. J. Mater. Chem. A., 1 (2013), pp. 7673-7680.

30. I.R. Gibson, G.P. Dransfield, J.T.S. Irvine. Sinterability of commercial $8 \mathrm{~mol} \%$ yttria-stabilized zirconia powders and the effect of sintered density on the ionic conductivity. J. Mater. Sci., 33 (1998), pp. 4297-4305.

31. P.S. Manning, J.D. Sirman, R.A. De Souza, J.A. Kilner. The kinetics of oxygen transport in $9.5 \mathrm{~mol} \%$ single crystal yttria stabilised zirconia. Solid State Ion., 100 (1997), pp. 1-10.

32. A. Weyl, D. Janke. High-temperature lonic conduction in multicomponent solid oxide solutions based on HfO2. J. Am. Ceram. Soc., 79 (1996), pp. 2145-2155. 
33. V. Šály, M. Hartmanová, V.B. Glushková. Electrical behaviour of $\mathrm{HfO}_{2}$ stabilized with rare earths. Solid State lon., 36 (1989), pp. 189-192.

34. M. Hartmanová, F. Hanic, K. Putyera, D. Tunega, V.B. Glushkova. Structure and physical properties of stabilized $\mathrm{HfO}_{2}-\mathrm{R}_{2} \mathrm{O}_{3}(\mathrm{R}=$ Sc, Yb, Y, Tb, Gd, Er). Mater. Chem. Phys., 34 (1993), pp. 175-180.

35. D.-J. Kim. Lattice parameters, ionic conductivities, and solubility limits in fluorite-structure $\mathrm{MO}_{2}$ oxide $\left[\mathrm{M}=\mathrm{Hf}^{4+}, \mathrm{Zr}^{4+}, \mathrm{Ce}^{4+}, \mathrm{Th}^{4+}\right.$, $\mathrm{U}^{4+}$ ] solid solutions. J. Am. Ceram. Soc., 72 (1989), pp. 1415-1421.

36. M. Mogensen, D. Lybye, N. Bonanos, P.V. Hendriksen, F.W. Poulsen. Factors controlling the oxide ion conductivity of fluorite and perovskite structured oxides. Solid State Ion., 174 (2004), pp. 279-286.

37. M.C. Steil, F. Thevenot, M. Kleitz. Densification of yttria-stabilized zirconia: impedance spectroscopy analysis. J. Electrochem. Soc., 144 (1997), pp. 390-398.

38. P.-M. Geffroy, et al. Influence of oxygen partial pressure on the oxygen diffusion and surface exchange coefficients in mixed conductors. J. Eur. Ceram. Soc., 39 (2019), pp. 59-65.

39. R.-N. Vannier, et al. Oxide ion transport in bismuth-based materials, 756 (2003), pp. 95-103.

40. F. Mauvy, et al. Chemical oxygen diffusion coefficient measurement by conductivity relaxation - correlation between tracer diffusion coefficient and chemical diffusion coefficient. J. Eur. Ceram. Soc., 24 (2004), pp. 1265-1269.

41. H. Ullmann, N. Trofimenko, F. Tietz, D. Stöver, A. Ahmad-Khanlou. Correlation between thermal expansion and oxide ion transport in mixed conducting perovskite-type oxides for SOFC cathodes. Solid State Ion., 138 (2000), pp. 79-90.

42. C. Déportes, et al. Electrochimie Des Solides. Presses Universitaires de Grenoble (1994).

43. D. Zhu, R.A. Miller. Sintering and creep behavior of plasma-sprayed zirconia and hafnia-based thermal barrier coatings. Surf. Coat. Technol., 108-109 (1998), pp. 114-120.

44. Zhang Wei, Chen Wen-Zhou, Sun Jiu-Yu, Jiang Zhen-Yi. Theoretical prediction of ion conductivity in solid state $\mathrm{HfO}_{2}$. Chinese Phys. B, 22 (2013), pp. 016601-1-016601-6.

45. R.J. Stafford, S.J. Rothman, J.L. Routbort. Effect of dopant size on the ionic conductivity of cubic stabilised $\mathrm{ZrO}_{2}$. Solid State Ion., 37 (1989), pp. 67-72.

46. R.P. Ingel, D.L. liiLattice parameters and density for $\mathrm{Y}_{2} \mathrm{O}_{3}$-Stabilized $\mathrm{ZrO}_{2}$. J. Am. Ceram. Soc., 69 (1986), pp. $325-332$.

47. C. Karthik, T.J. Anderson, D. Gout, R. Ubic. Transmission electron microscopic study of pyrochlore to defect-fluorite transition in rare-earth pyrohafnates. J. Solid State Chem., 194 (2012), pp. 168-172.

48. M.A. Subramanian, G. Aravamudan, G.V. Subba RaoOxide pyrochlores - a review. Prog. Solid State Chem., 15 (1983), pp. 55143.

49. V.V. Popov, et al. Fluorite-pyrochlore phase transition in nanostructured Ln2Hf2O7 (Ln = La-Lu). J. Alloys. Compd., 689 (2016), pp. 669-679.

50. B.P. Mandal, N. Garg, S.M. Sharma, A.K. Tyagi. Preparation, XRD and Raman spectroscopic studies on new compounds $\mathrm{RE}_{2} \mathrm{Hf}_{2} \mathrm{O}_{7}(\mathrm{RE}=\mathrm{Dy}, \mathrm{Ho}, \mathrm{Er}, \mathrm{Tm}, \mathrm{Lu}, \mathrm{Y})$ : Pyrochlores or defect-fluorite? J. Solid State Chem., 179 (2006), pp. 1990-1994.

51. M. Duclot, J. Vicat, C. DeportesMise en évidence et étude de la phase ordonnée $\mathrm{Y}_{2} \mathrm{Hf}_{7} \mathrm{O}_{17}$ dans le système $\mathrm{HfO}_{2}-\mathrm{Y}_{2} \mathrm{O}_{3}$. J. Solid State Chem., 2 (1970), pp. 236-249.

52. A. Tschöpe, E. Sommer, R. Birringer. Grain size-dependent electrical conductivity of polycrystalline cerium oxide: I. Experiments. Solid State Ion., 139 (2001), pp. 255-265.

53. S. Sameshima, M. Kawaminami, Y. Hirata. Thermal expansion of rare-earth-doped ceria ceramics. J. Ceram. Soc. Jpn., 110 (2002), pp. 597-600.

54. C. Li, et al. Effect of $Y$ doping on microstructure and thermophysical properties of yttria stabilized hafnia ceramics. Ceram. Int., 44 (2018), pp. 18213-18221.

55. H. Lehmann, D. Pitzer, G. Pracht, R. Vassen, D. Stöver. Thermal conductivity and thermal expansion coefficients of the lanthanum rare-earth-Element zirconate system. J. Am. Ceram. Soc., 86 (2003), pp. 1338-1344.

56. Z. Hongsong, S. Lei, Z. Yongde, L. Gang, L. Zhenjun. Thermal conductivities and thermal expansion coefficients of $\left(\mathrm{Sm}_{0.5} \mathrm{Gd}_{0.5}\right)_{2}\left(\mathrm{Ce}_{1-\mathrm{x}} \mathrm{Zr}_{\mathrm{x}}\right)_{2} \mathrm{O}_{7}$ ceramics. J. Mater. Eng. Perform., 24 (2015), pp. 3394-3399.

57. T.L. Cottrell. The Strengths of Chemical Bonds. (Butterworth, 1958). (1958).

58. D. Marrocchelli, S.R. Bishop, H.L. Tuller, B. Yildiz. Understanding chemical expansion in non-stoichiometric oxides: ceria and zirconia case studies. Adv. Funct. Mater., 22 (2012), pp. 1958-1965.

59. M. Meyer, N. Nicoloso, V. Jaenisch. Percolation model for the anomalous conductivity of fluorite-related oxides. Phys. Rev. B, 56 (1997), pp. 5961-5966.

60. M. Yashima, N. Ishizawa, M. Yoshimura. Application of an ion-packing model based on defect clusters to zirconia solid solutions: I, modeling and local structure of solid solutions. J. Am. Ceram. Soc., 75 (1992), pp. 1541-1549.

61. S.R. Bishop, K.L. Duncan, E.D. Wachsman. Surface and bulk oxygen non-stoichiometry and bulk chemical expansion in gadolinium-doped cerium oxide. Acta Mater., 57 (2009), pp. 3596-3605.

62. L.-W. Tai, M.M. Nasrallah, H.U. Anderson, D.M. Sparlin, S.R. Sehlin. Structure and electrical properties of $\mathrm{La}_{1-\mathrm{x}} \mathrm{Sr}_{\mathrm{x}} \mathrm{Co}_{1-\mathrm{y}} \mathrm{Fe}_{\mathrm{y}} \mathrm{O}_{3}$. Part 2. The system $\mathrm{La}_{1-x} \mathrm{Sr}_{x} \mathrm{CO}_{0.2} \mathrm{Fe}_{0.8} \mathrm{O}_{3}$. Solid State Ion., 76 (1995), pp. 273-283.

63. F. Tietz. Thermal expansion of SOFC materials. Ionics, 5 (1999), pp. 129-139.

64. A. Rolle, V. Thoreton, C. Pirovano, O. Lafon, R.-N. Vannier. Conducteurs ioniques par ions oxyde. Tech. Ing. Fondam. En Chim. (2015).

65. C. Monty. About ionic conductivity/diffusion relationships in yttria doped zirconia. lonics, 8 (2002), pp. $461-469$.

66. S.J. Hong, K. Mehta, A.V. Virkar. Effect of microstructure and composition on ionic conductivity of rare-earth oxide-doped Ceria. J. Electrochem. Soc., 145 (1998), pp. 638-647. 
67. M. Legallais, et al. Fast re-oxidation kinetics and conduction pathway in Spark Plasma Sintered ferroelectric ceramics. J. Eur. Ceram. Soc., 38 (2018), pp. 543-550.

68. C. Ahamer, A.K. Opitz, G.M. Rupp, J. Fleig. Revisiting the temperature dependent ionic conductivity of yttria stabilized zirconia (YSZ). J. Electrochem. Soc., 164 (2017), pp. F790-F803.

69. D.W. Strickler, W.G. Carlson. Ionic conductivity of cubic solid solutions in the system $\mathrm{CaO}-\mathrm{Y}_{2} \mathrm{O}_{3}-\mathrm{ZrO}_{2} \mathrm{Oxygen}$. J. Am. Ceram. Soc., 47 (1964), pp. 122-127.

70. M. Burbano, et al. Oxygen vacancy ordering and the conductivity maximum in $\mathrm{Y}_{2} \mathrm{O}_{3}-$ Doped $\mathrm{CeO}_{2}$. Chem. Mater., 24 (2012), pp. 222-229.

71. J.D. Solier, I. Cachadina, A. Dominguez-Rodriguez. Ionic conductivity of ZrO 2-12 mol\% Y 203 single crystals. Phys. Rev. B, 48 (1993), p. 3704.

72. J.E. Bauerle. Study of solid electrolyte polarization by a complex admittance method. J. Phys. Chem. Solids, 30 (1969), pp. 2657-2670.

73. D.K. Hohnke. Ionic conduction in doped oxides with the fluorite structure. Solid State Ion., 5 (1981), pp. 531-534.

74. J. Zhang, C. Lenser, N.H. Menzler, O. Guillon. Comparison of solid oxide fuel cell (SOFC) electrolyte materials for operation at $500{ }^{\circ} \mathrm{C}$. Solid State Ion., 344 (2020), Article 115138.

75. J.A. Kilner, R.J. BrookA study of oxygen ion conductivity in doped non-stoichiometric oxides. Solid State lon., 6 (1982), pp. 237252.

76. S. Omar, E.D. Wachsman, J.L. Jones, J.C. Nino. Crystal structure-lonic conductivity relationships in doped Ceria systems. J. Am. Ceram. Soc., 92 (2009), pp. 2674-2681.

77. M. Hartmanová, et al. Relationship between effective ionic radii, structure and electro-mechanical properties of zirconia stabilized with rare earth oxides $\mathrm{M}_{2} \mathrm{O}_{3}(\mathrm{M}=\mathrm{Yb}, \mathrm{Y}, \mathrm{Sm})$. J. Mater. Sci., 44 (2009), pp. 234-243.

78. D.W. Strickler, W.G. Carlson. Electrical conductivity in the $\mathrm{ZrO}_{2}-$ Rich region of several $\mathrm{M}_{2} \mathrm{O}_{3}-\mathrm{ZrO}_{2}$ systems. J. Am. Ceram. Soc., 48 (1965), pp. 286-289.

79. F. Pietrucci, M. Bernasconi, A. Laio, M. Parrinello. Vacancy-vacancy interaction and oxygen diffusion in stabilized $\mathrm{cubic} \mathrm{ZrO}_{2}$ from first principles. Phys. Rev. B, 78 (2008), Article 094301.

80. J. Kondoh, S. Kikuchi, Y. Tomii, Y. Ito. Effect of aging on yttria-stabilized zirconia III. A study of the effect of local structures on conductivity. J. Electrochem. Soc., 145 (1998), pp. 1550-1560. 
Table 1

Theoretical density, apparent density, total and open porosity of samples

\begin{tabular}{|c|c|c|c|c|c|c|c|}
\hline $\begin{array}{l}\text { Dopant content (mol\% } \\
\mathrm{Y}_{2} \mathrm{O}_{3} \text { ) }\end{array}$ & Solid solution composition & Reference $^{a}$ & $\begin{array}{l}\text { Theoretical density }{ }^{\mathrm{b}}(\mathrm{g} / \\
\mathrm{cm}^{3} \text { ) }\end{array}$ & $\begin{array}{l}\text { Apparent density }(\mathrm{g} / \\
\mathrm{cm}^{3} \text { ) }\end{array}$ & $\begin{array}{l}\text { Open porosity } \\
(\%)\end{array}$ & $\begin{array}{l}\text { Total porosity } \\
(\%)\end{array}$ & $\begin{array}{l}\text { Average grain size } \\
(\mu \mathrm{m})\end{array}$ \\
\hline 12 & $\mathrm{Hf}_{0.786} \mathrm{Y}_{0.214} \mathrm{O}_{1.893}$ & Y-12 & 9.329 & 9.12 & 0.2 & 2.3 & 19.1 \\
\hline 14 & $\mathrm{Hf}_{0.754} \mathrm{Y}_{0.246} \mathrm{O}_{1.877}$ & Y-14 & 9.157 & 8.92 & 0.6 & 2.6 & 17.4 \\
\hline 20 & $\mathrm{Hf}_{0.666} \mathrm{Y}_{0.333} \mathrm{O}_{1.834}$ & $\mathrm{Y}-20$ & 8.679 & 8.66 & 0.4 & 0.4 & 15.6 \\
\hline 33 & $\mathrm{Hf}_{0.5} \mathrm{Y}_{0.5} \mathrm{O}_{1.75}$ & Y-33 & 7.704 & 7.72 & 0.2 & 0 & 14.4 \\
\hline
\end{tabular}

a $\mathrm{Y}$-molar percentage of $\mathrm{Y}_{2} \mathrm{O}_{3}$

${ }^{b}$ Calculated form Rietveld analysis.

Table 2

Comparison of the theoretical and measured (ICP-OES and EDX) Hf and Y weight contents. Quantification of O is not included, values are obtained by stoichiometry Standard deviation measurements are between brackets (\%) and $\Delta$ is the ratio of the measured element content to the theoretical element content (\%).

\begin{tabular}{|c|c|c|c|c|c|c|c|c|c|c|}
\hline \multirow[t]{2}{*}{ Ref. } & \multicolumn{2}{|c|}{ Theoretical weight element content (\%) } & \multicolumn{4}{|c|}{ Weight element content by ICP-OES (\%) } & \multicolumn{4}{|c|}{ Weight element content by EDS (\%) } \\
\hline & Hf & $\mathrm{Y}$ & Hf & $\Delta$ & $\mathrm{Y}$ & $\Delta$ & $\mathrm{Hf}$ & $\Delta$ & $\mathrm{Y}$ & $\Delta$ \\
\hline $\mathrm{Y}-12$ & 73.97 & 10.05 & 73.09 (1.07) & 1.2 & $10.49(0.24)$ & 4.4 & $73.6(0.5)$ & 0.5 & $10.4(0.6)$ & 3.5 \\
\hline Y-14 & 72.19 & 11.71 & $71.39(0.89)$ & 1.1 & $12.23(0.20)$ & 4.5 & $72.3(0.4)$ & 0.2 & $12.0(0.6)$ & 2.5 \\
\hline $\mathrm{Y}-20$ & 66.87 & 16.65 & $65.87(0.43)$ & 1.5 & $17.34(0.28)$ & 4.1 & $67.1(1.4)$ & 0.4 & $16.7(0.9)$ & 0.3 \\
\hline $\mathrm{Y}-33$ & 55.48 & 27.22 & $55.63(0.36)$ & 0.3 & $28.20(0.32)$ & 3.6 & $55.4(0.2)$ & 0.1 & $27.4(0.6)$ & 0.6 \\
\hline
\end{tabular}

Table 3

Ionic radius, atomic weight and binding energy of ions from studied oxides [57].

\begin{tabular}{lll}
\hline & $\mathrm{Hf}^{4+}$ & $\mathrm{Y}^{3+}$ \\
\hline Ionic radius $(\AA)$ & 0.83 & 1.019 \\
$\Delta H_{f(298)}(\mathrm{RE}-\mathrm{O})(\mathrm{kJ} / \mathrm{mol})$ & $791+/-8$ & $715+/-30$ \\
Atomic weight $(\mathrm{g} / \mathrm{mol})$ & 178.49 & 88.91 \\
\hline
\end{tabular}

Table 4

Activation energy as a function of doping content considering association/dissociation model.

\begin{tabular}{rllll}
\hline Samples & \multicolumn{2}{l}{ Activation energy $(\mathrm{eV})$} & $\begin{array}{l}\text { Association } \\
\text { energy }(\mathrm{eV})\end{array}$ & $\begin{array}{l}\text { Migration } \\
\text { energy }(\mathrm{eV})\end{array}$ \\
\cline { 2 - 4 } & $580-870 \mathrm{~K}$ & $870-1300 \mathrm{~K}$ & & 0.92 \\
\hline $\begin{array}{r}12 \mathrm{~mol} \% \\
\mathrm{Y}_{2} \mathrm{O}_{3}\end{array}$ & 1.26 & 0.92 & 0.34 & 1.03 \\
$\begin{array}{r}14 \mathrm{~mol} \% \\
\mathrm{Y}_{2} \mathrm{O}_{3}\end{array}$ & 1.40 & 1.03 & 0.37 & - \\
$\begin{array}{r}20 \mathrm{~mol} \% \\
\mathrm{Y}_{2} \mathrm{O}_{3}\end{array}$ & 1.44 & 1.37 & - & - \\
$\begin{array}{r}33 \mathrm{~mol} \% \\
\mathrm{Y}_{2} \mathrm{O}_{3}\end{array}$ & 1.39 & 1.16 & - & \\
\hline
\end{tabular}

Table 5

Fit parameters of the two barrier model as function of dopant content.

\begin{tabular}{lllllll}
\hline Sample & Ref. & $E_{a, 1}(\mathrm{eV})$ & $E_{a, 2}(\mathrm{eV})$ & $\gamma_{1}(\mathrm{~K} . \mathrm{S} / \mathrm{cm})$ & $\gamma_{2}(\mathrm{~K} . \mathrm{S} / \mathrm{cm})$ & $\gamma_{2} / \gamma_{1}$ \\
\hline $12 \mathrm{~mol} \% \mathrm{Y}_{2} \mathrm{O}_{3}$ & $\mathrm{Y}-12$ & 0.66 & 1.40 & $1.3 \cdot 10^{4}$ & $1.1 \cdot 10^{8}$ & $9.1 \cdot 10^{3}$ \\
$14 \mathrm{~mol} \% \mathrm{Y}_{2} \mathrm{O}_{3}$ & $\mathrm{Y}-14$ & 0.64 & 1.50 & $0.7 \cdot 10^{4}$ & $1.6 \cdot 10^{8}$ & $2.4 \cdot 10^{4}$ \\
$20 \mathrm{~mol} \% \mathrm{Y}_{2} \mathrm{O}_{3}$ & $\mathrm{Y}-20$ & 1.42 & 1.42 & $7.1 \cdot 10^{6}$ & $1.2 \cdot 10^{9}$ & $1.7 \cdot 10^{2}$ \\
$33 \mathrm{~mol} \% \mathrm{Y}_{2} \mathrm{O}_{3}$ & $\mathrm{Y}-33$ & 1.10 & 1.60 & $1.6 \cdot 10^{4}$ & $4.4 \cdot 10^{7}$ & $2.8 \cdot 10^{4}$ \\
\hline
\end{tabular}




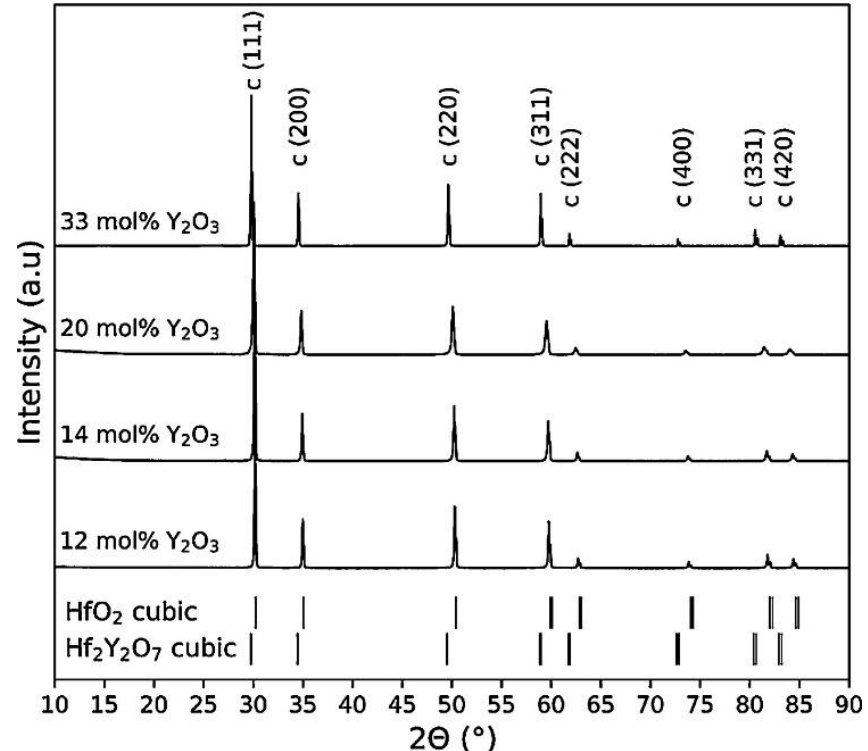

Fig. 1. X-Ray diffraction patterns of $\mathrm{HfO}_{2}-\mathrm{Y}_{2} \mathrm{O}_{3}$ samples as a function of the $\mathrm{Y}_{2} \mathrm{O}_{3}$ concentration.

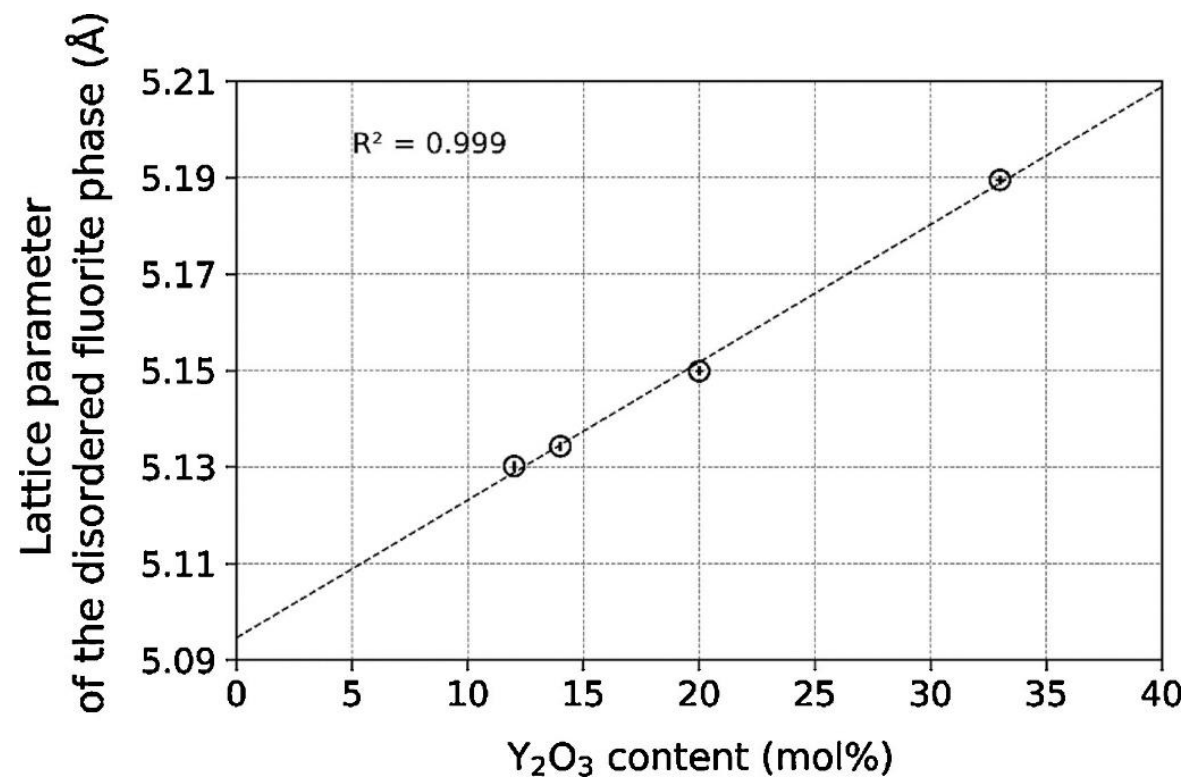

Fig. 2. Measured lattice parameters of $\mathrm{YSH}$ solid solutions as a function of $\mathrm{Y}_{2} \mathrm{O}_{3}$ doping contents. 


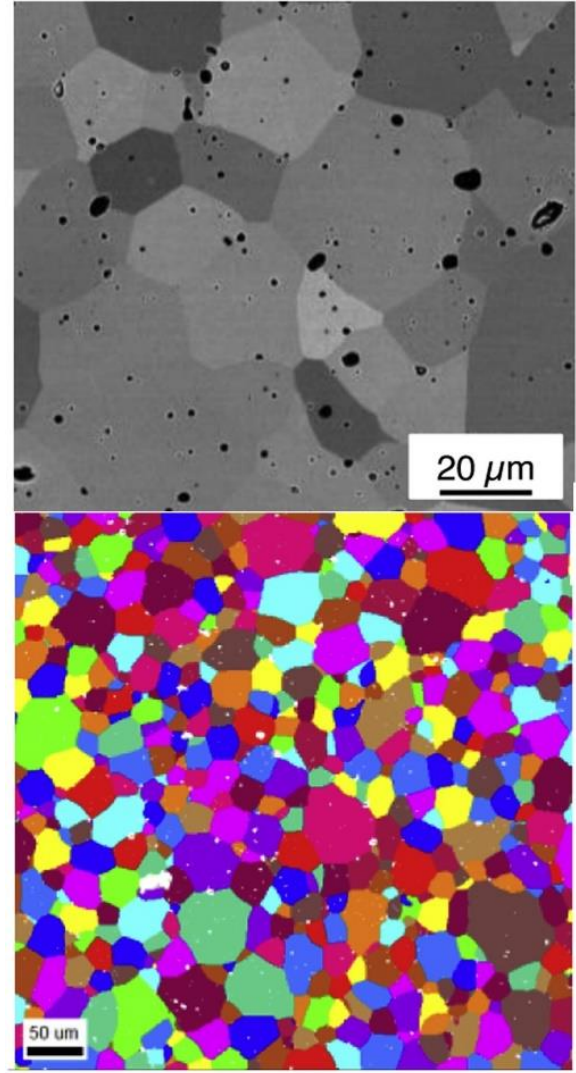

(a)

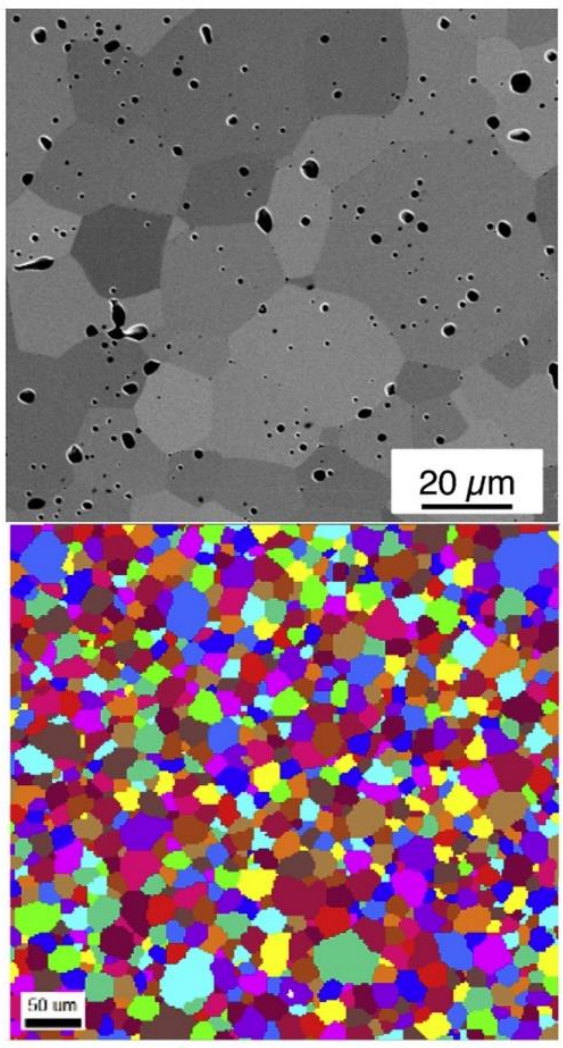

(c)

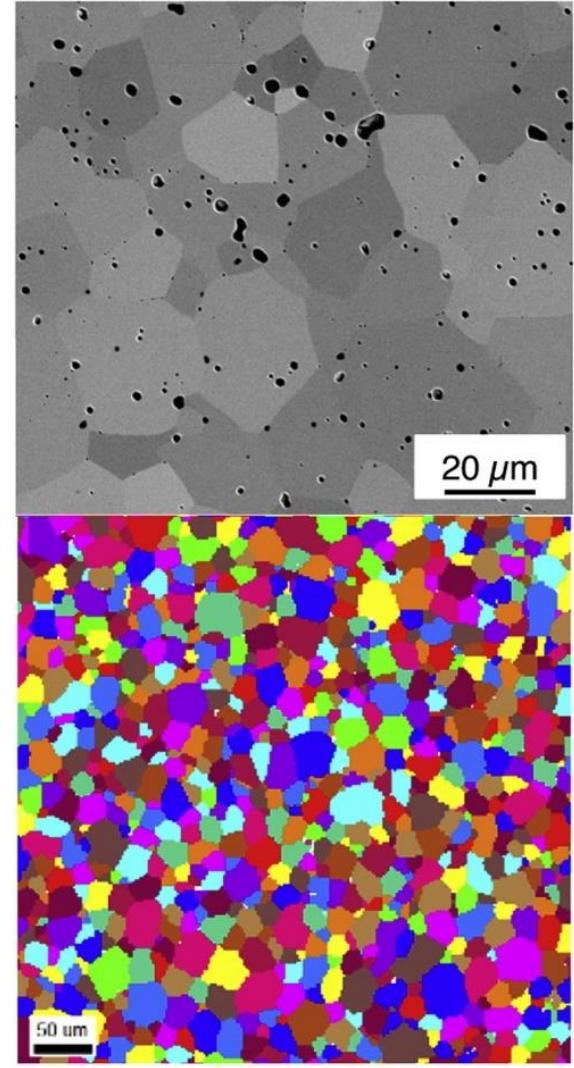

(b)

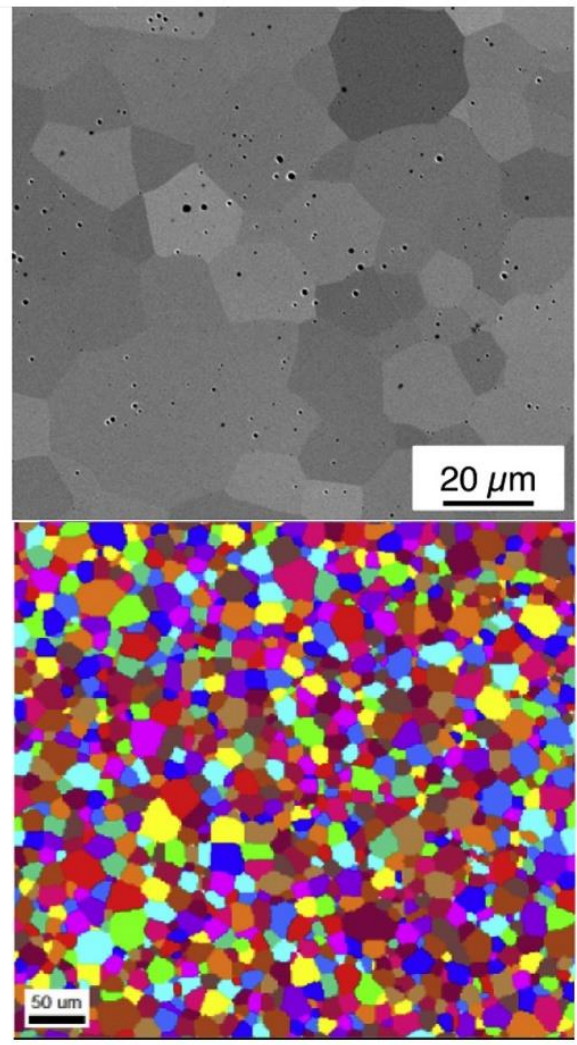

(d)

Fig. 3. BSE observations and EBSD cartographies of samples (a) Y-12, (b) Y-14, (c) Y-20 and (d) Y-33. 


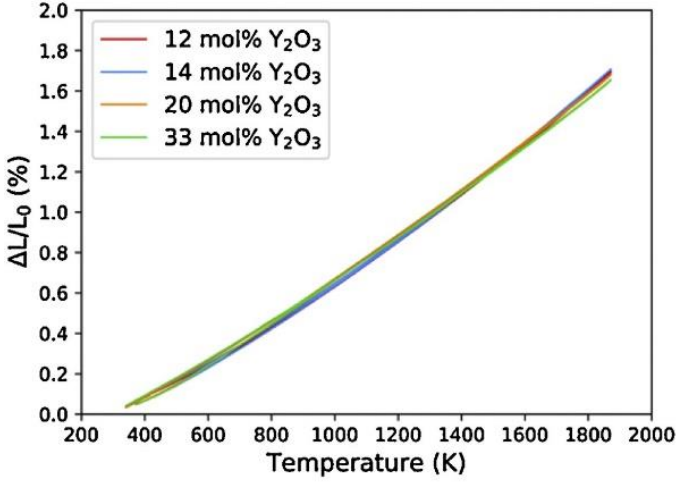

(a)

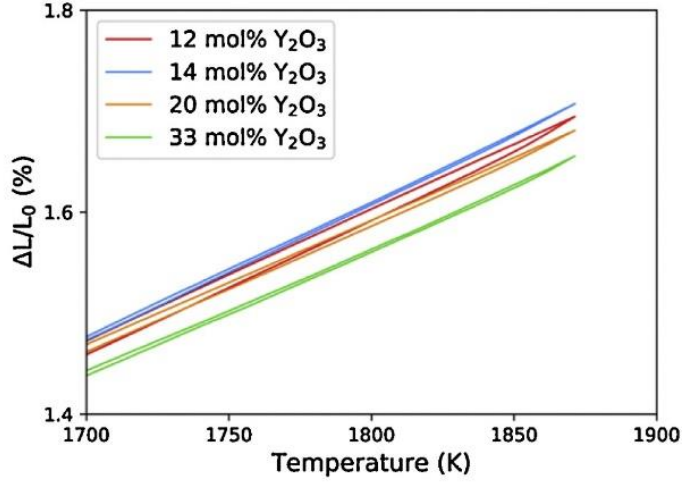

(b)

Fig. 4. Linear thermal expansion and contraction of studied samples as a function of the temperature (under a $20 \mathrm{~mL} / \mathrm{min}$ air flow) (a) all range of temperature (b) temperature from $1700 \mathrm{~K}$ to $1873 \mathrm{~K}$ (heating/cooling rate: $5 \mathrm{~K} / \mathrm{min}$ ).

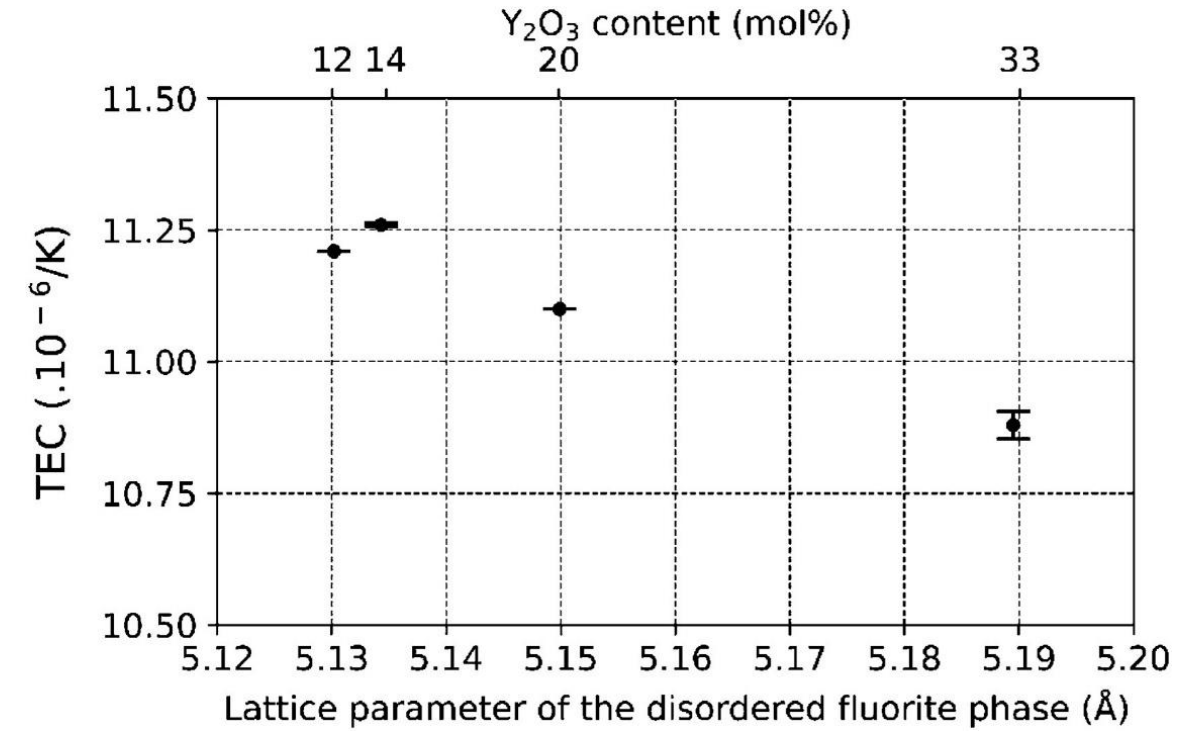

Fig. 5. $\mathrm{HfO}_{2}-\mathrm{Y}_{2} \mathrm{O}_{3}$ thermal expansion coefficient as a function of the lattice parameter of the fluorite phase with the corresponding concentration of $\mathrm{Y}_{2} \mathrm{O}_{3}(500-1830 \mathrm{~K})$.

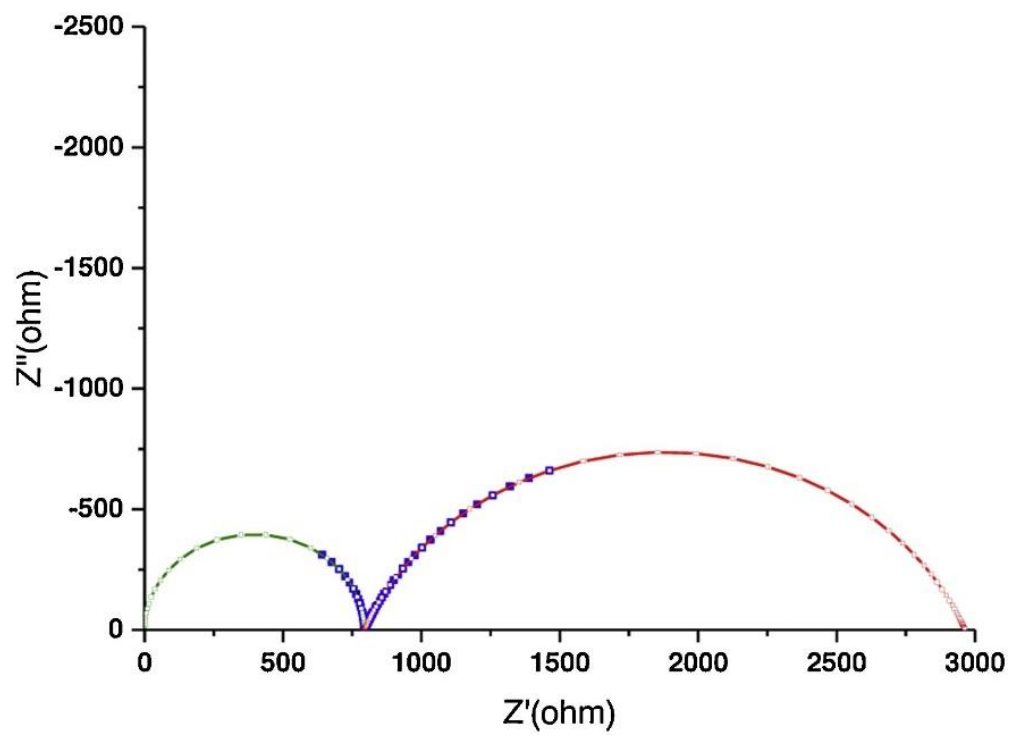

Fig. 6. Impedance spectrum of the $\mathrm{Pt} / \mathrm{HfO}_{2}-\mathrm{Y}_{2} \mathrm{O}_{3} / \mathrm{Pt}$ cell measured at $835 \mathrm{~K}$ with fit curve. 


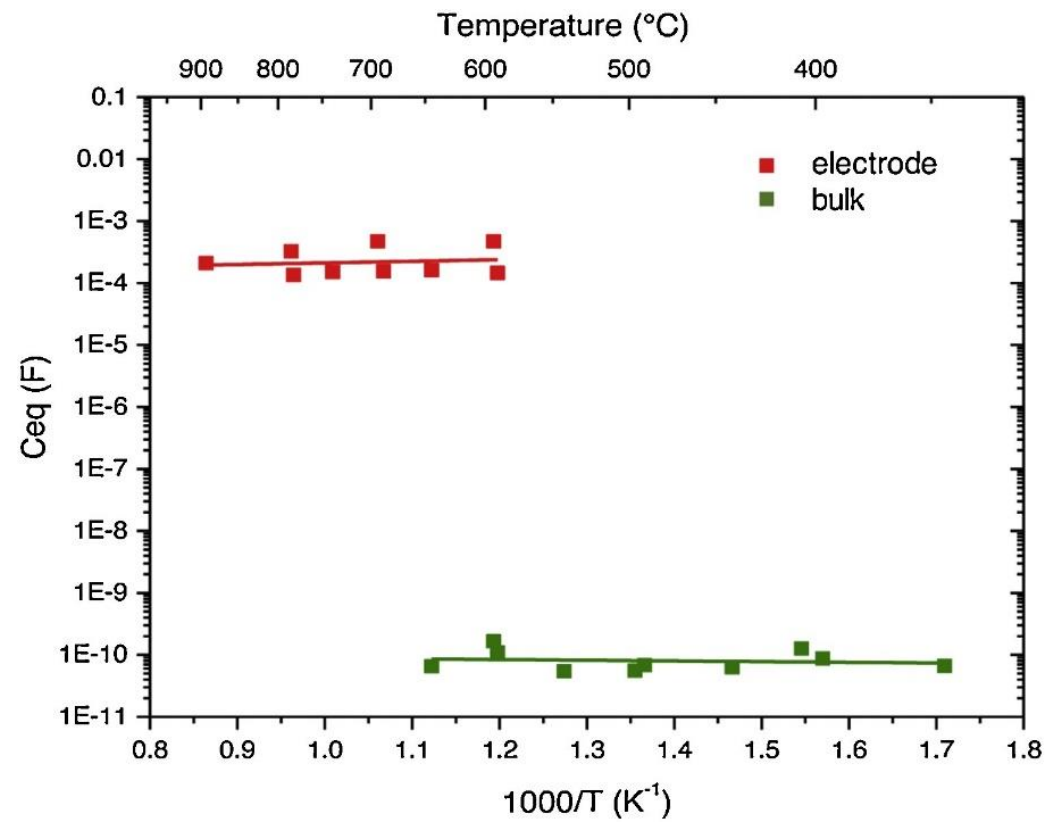

Fig. 7. Arrhenius plot of the capacitance contribution characterising of the electrode (in red) and the bulk (in green) for a $12 \mathrm{~mol} \% \mathrm{Y}_{2} \mathrm{O}_{3}$ sample (For interpretation of the references to colour in this figure legend, the reader is referred to the web version of this article).

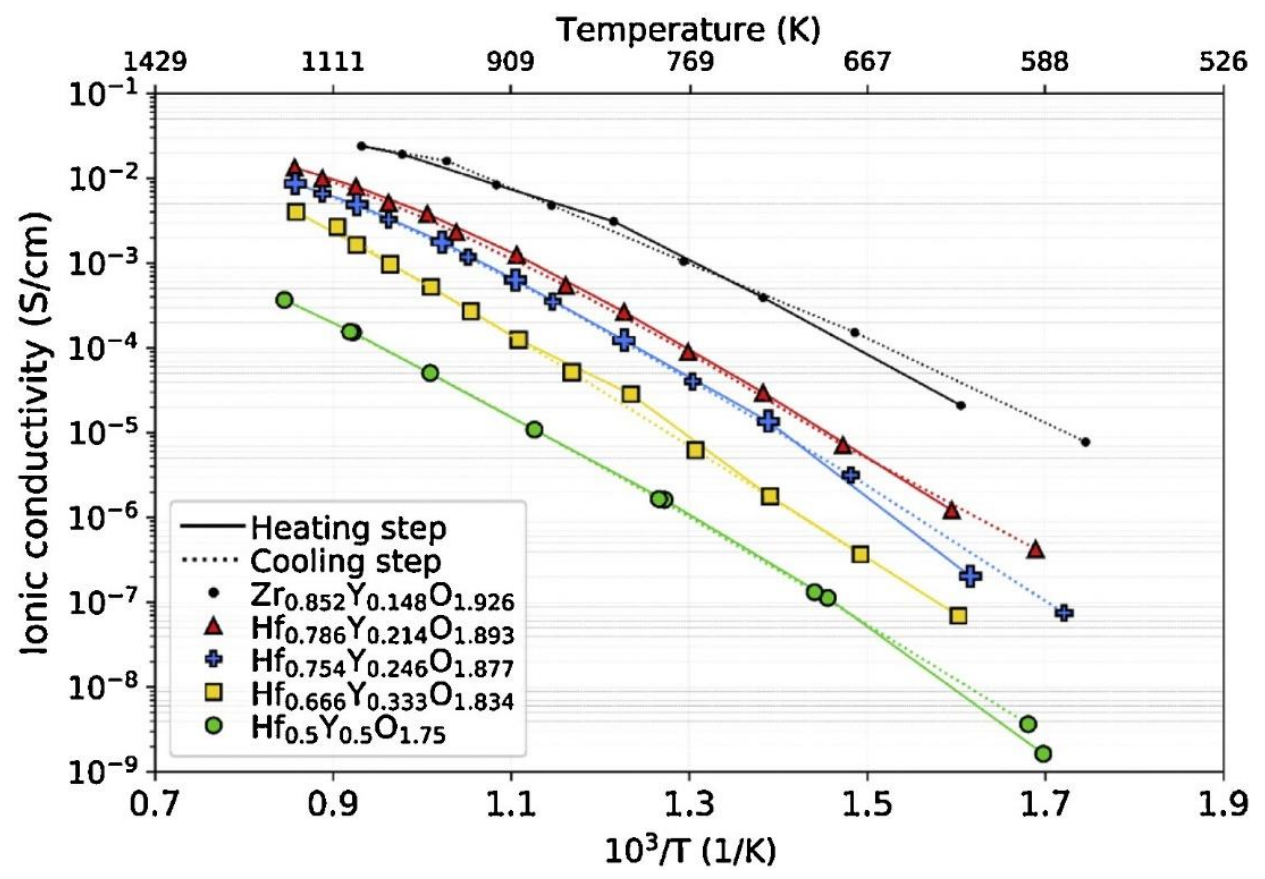

Fig. 8. Ionic conductivity of various compositions of stabilised hafnia samples as a function of temperature and compared with data of 8YSZ (from this work). 


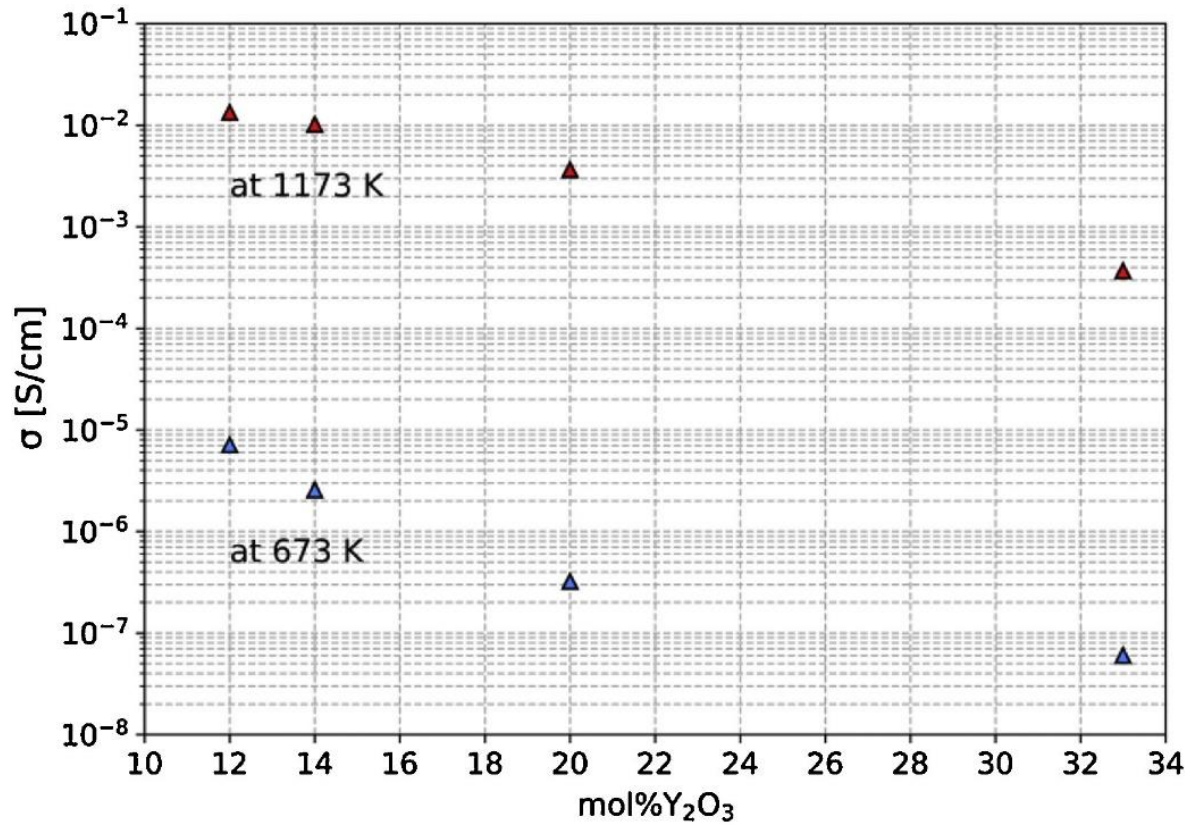

Fig. 9. Influence of the dopant content on the ionic conductivity at 673 and $1173 \mathrm{~K}$. 


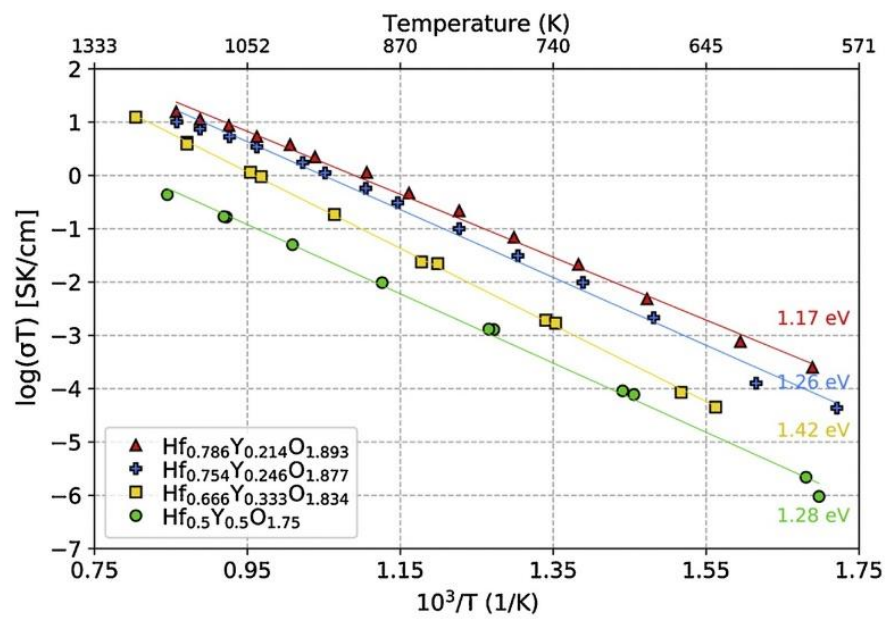

(a)

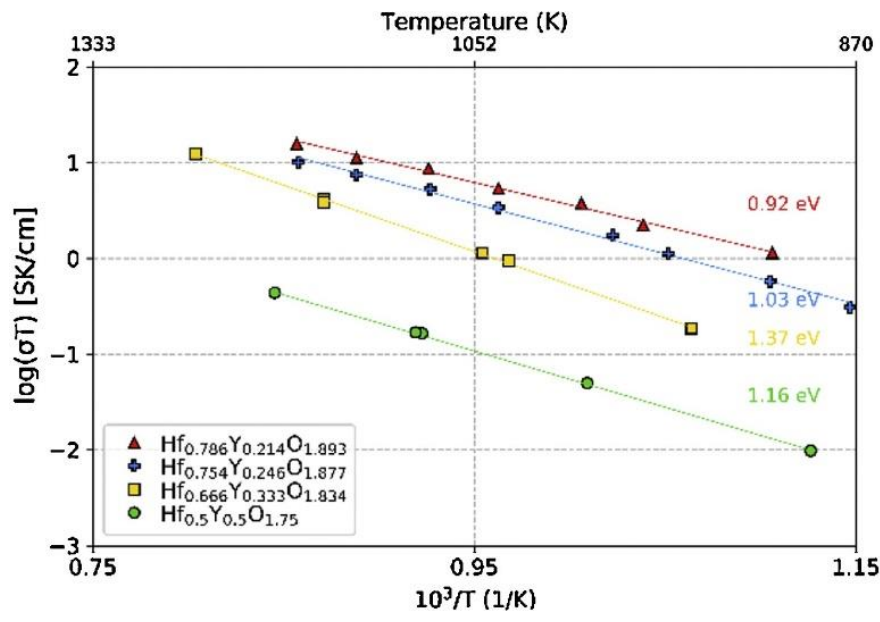

(b)

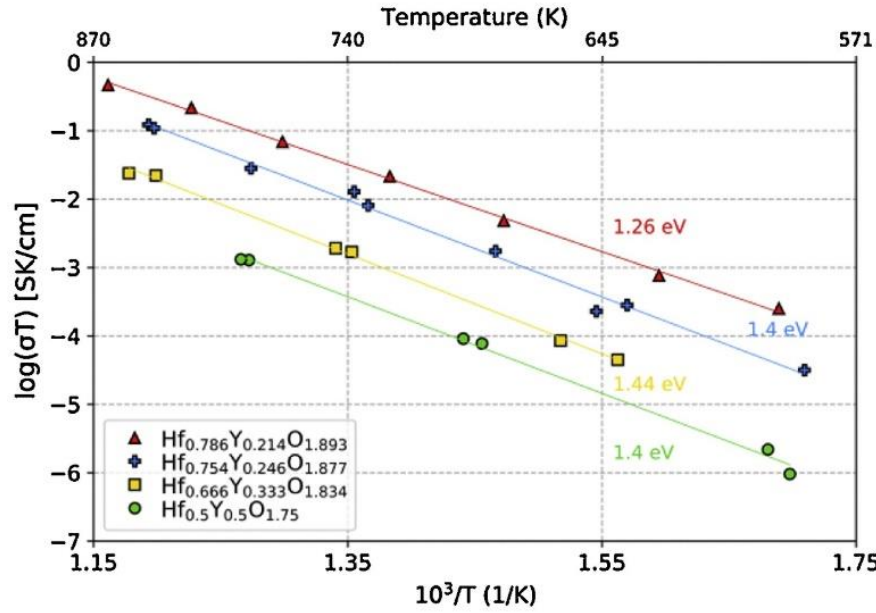

(c)

Fig. 10. Arrhenius plots of the $\mathrm{Hf}_{1-\mathrm{x}} \mathrm{Y}_{\mathrm{x}} \mathrm{O}_{2-\mathrm{x} / 2}(\mathrm{x}=0.214,0.286,0.333,0.5)$ samples in the entire range of temperature (a), at high temperature range $(\mathrm{b})$, and low temperature range $(\mathrm{c})$. 


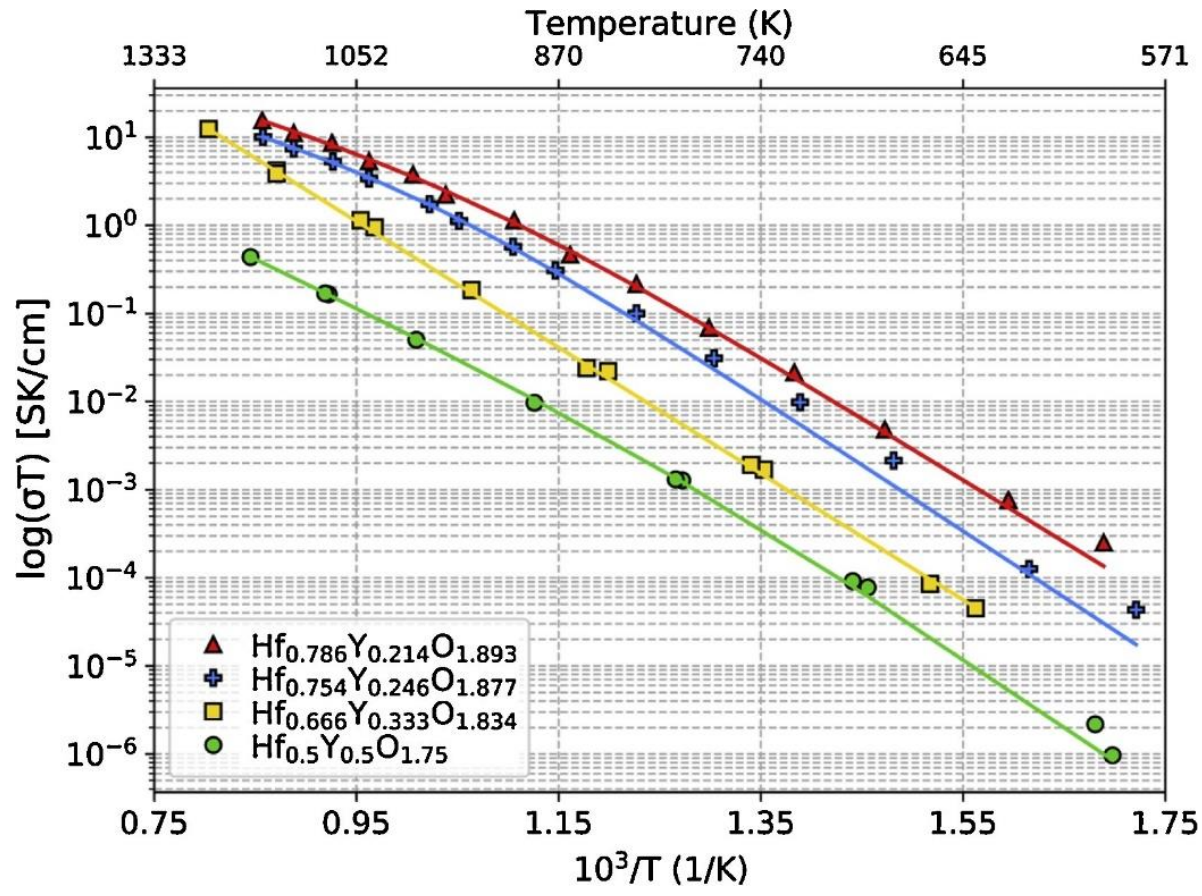

Fig. 11. Two barriers model fits experimental data. 